\title{
Phylogeny and evolution of habitat preference in Goniurosaurus (Squamata: Eublepharidae) and their correlation with karst and granite-stream-adapted ecomorphologies in species groups from Vietnam
}

L. Lee Grismer ${ }^{1}$, Hai Ngoc Ngo ${ }^{2,3,4}$ Shuo Qi ${ }^{5}$, Ying-Yong Wang ${ }^{5}$, Minh Duc Le ${ }^{6,7,8}$,Thomas Ziegler ${ }^{3,4}$

1 Herpetology Laboratory, Department of Biology, La Sierra University, Riverside, CA, USA

2 Vietnam National Museum of Nature, Vietnam Academy of Science and Technology, 18 Hoang Quoc Viet Road, Hanoi, Vietnam

3 Institute of Zoology, University of Cologne, Zülpicher Strasse 47b, 50674, Germany

4 Cologne Zoo, Riehler Straße 173, 50735, Cologne, Germany

5 State Key Laboratory of Biocontrol/The Museum of Biology, School of Life Sciences, Sun Yat-sen University, Guangzhou, Guangdong 510275, China

6 Department of Environmental Ecology, Faculty of Environmental Sciences, University of Science, Vietnam National University, Hanoi, 334 Nguyen Trai Road, Hanoi, Vietnam

7 Central Institute for Natural Resources and Environmental Studies, Vietnam National University, Hanoi, 19 Le Thanh Tong Street, Hanoi, Vietnam

8 Department of Herpetology, American Museum of Natural History, Central Park West at 79 th Street, New York, New York 10024, USA

http://zoobank.org/7B2E512E-5FA5-4F89-A7AC-8F0AC6EEDA59

Corresponding author: L. Lee Grismer (lgrismer@lasierra.edu)

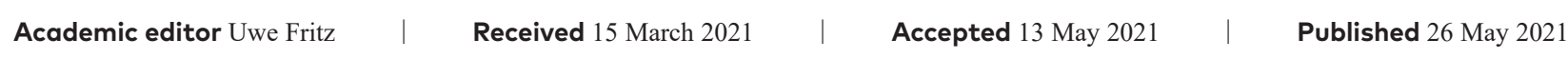

Citation: Grismer LL, Ngo HN, Qi S, Wang YY, Le MD, Ziegler T (2021) Phylogeny and evolution of habitat preference in Goniurosaurus (Squamata: Eublepharidae) and their correlation with karst and granite-stream-adapted ecomorphologies in species groups from Vietnam. Vertebrate Zoology 71: 335-352. https://doi.org/10.3897/vz.71.e65969

\begin{abstract}
Maximum likelihood (ML) and Bayesian inference (BI) analyses using two mitochondrial (16S and cyt $b$ ) and two nuclear (CMOS and RAG1) genes and 103 specimens recovered the first phylogenies of all 23 extant species of Goniurosaurus. The analyses strongly supported the recognition of four monophyletic species groups with identical inter-specific relationships within the kuroiwae, lichtenfelderi, and yingdeensis groups but discordant topologies at some nodes within the luii group. Both analyses recovered a polyphyletic G. luii with respect to G. kadoorieorum, and owing to the lack of diagnostic characters in the latter, it is considered a junior synonym of G. luii. A stochastic character mapping analysis of karst versus non-karst habitat preference suggested that karstic landscapes may have played a major role in the evolution and diversification of Goniurosaurus. A karst habitat preference is marginally supported as the most probable ancestral condition for Goniurosaurus as well as for the kuroiwae, luii, and yingdeensis groups. However, a nonkarst habitat preference is marginally supported as the most probable ancestral condition for the lichtenfelderi group. Multivariate and univariate ecomorphological analyses of the karst-adapted G. catbaensis, G. huuliensis, and G. luii of the luii group and the granite-stream-adapted $G$. lichtenfelderi of the lichtenfelderi group demonstrated that their markedly statistically different body shapes may be an adaptive response that contributes to habitat partitioning in areas of northern Vietnam where they are nearly sympatric.
\end{abstract}

\section{Keywords}

Asia, stochastic character mapping, systematics, synonymy, tiger geckos

Copyright L. L. Grismer et al. This is an open access article distributed under the terms of the Creative Commons Attribution License (CC BY 4.0), which permits unrestricted use, distri bution, and reproduction in any medium, provided the original author and source are credited. 


\section{Introduction}

Eublepharid geckos of the genus Goniurosaurus Barbour, 1908 comprise 23 saxicolous specialists (Uetz et al. 2021) that extend from the Ryukyu Archipelago in Japan, southward through East Asia to northern Vietnam. Goniurosaurus is a well-defined monophyletic group (Grismer 1988) comprised of four monophyletic species groups: the kuroiwae group containing six species endemic to the Ryukyu Archipelago, Japan; the lichtenfelderi group with five species from insular and mainland China and northern Vietnam; the luii group with eight species from northern Vietnam, some of its offshore islands, and southern China; and the yingdeensis group consisting of four species from southern China (Kurita et al. 2008; Nguyen et al. 2009; Nguyen 2011; Wang et al. 2013; Honda and Ota 2017; Liang et al. 2018; Qi et al. 2020a, 2020b; Zhu et al. 2020a, 2020b). Apart from these species, Goniurosaurus sinensis Zhou, Peng, Huo and Yuan, 2019 is likely a junior synonym of another species from Hainan Island, China and not included herein (Qi et al. in progress). Phylogenetic relationships within Goniurosaurus have never been strongly supported nor consistent among different studies (e.g. Wang et al. 2013; Liang et al. 2018; Qi et al. 2020a, 2020b; Zhu et al. 2020a, 2020b). This protracted state of discordance results, in part, from researchers focusing on different species groups as opposed to the entire genus, as well as using different genes or different combinations of genes with varying combinations of ingroup and outgroup species - all variables that bear significantly on tree construction (Wiens 1998; Zwickl et al. 2002; Heath et al. 2008; Wiens and Morrill 2011; Wainwright and Price 2016). The most commonly used genetic markers have been the mitochondrial genes $12 \mathrm{~S}$ and 16S rRNA and cytochrome $b$ (cyt $b$ ). Liang et al. (2018) were the first to address the challenges of properly aligning rRNA (Pyron et al. 2013) and constructed a well-supported mito-nuclear data set using $16 \mathrm{~S}$, cyt $b$, and the nuclear genes oocyte maturation factor MOS (CMOS), and recombination activating 1 (RAG1). Zhu et al. (2020b) also used this mito-nuclear combination, but examined only relationships within the lichtenfelderi group.

In an effort to continue building a more global understanding of the phylogenetic relationships within Goniurosaurus, we expanded the mito-nuclear data set of Liang et al. (2018) to include 103 individuals as opposed to 31 and 23 as opposed to 17 species, which for the first time, includes all extant species of the genus (Table 1). We used this phylogeny in a stochastic character state mapping (SCM) analysis (Revell 2012) of habitat preference to explore the role karstic landscapes may have played in the evolution and diversification of Goniurosaurus and if

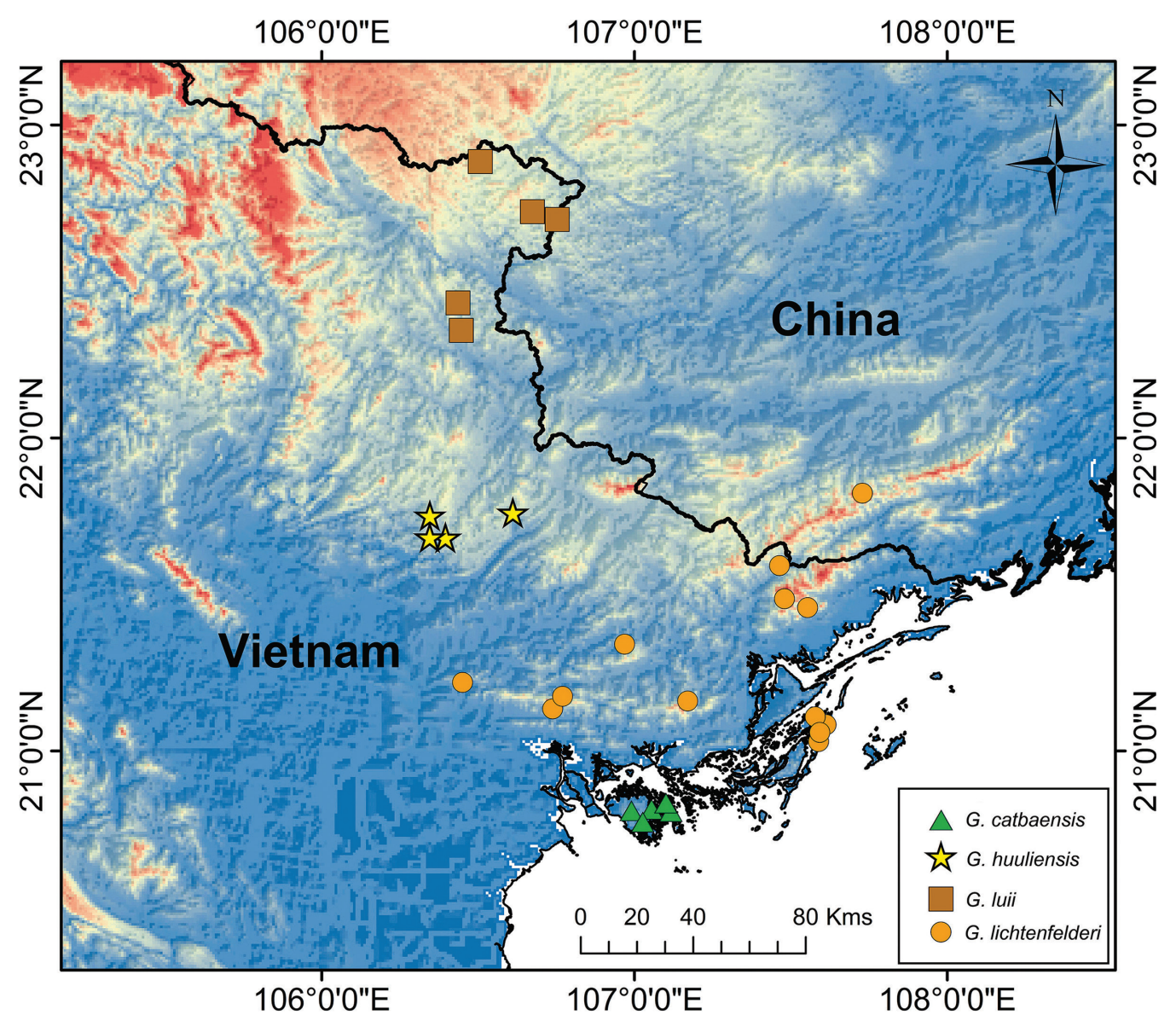

Figure 1. Distribution of the four recorded species of Goniurosaurus in Vietnam and China used in the ecomorphological analysis. 


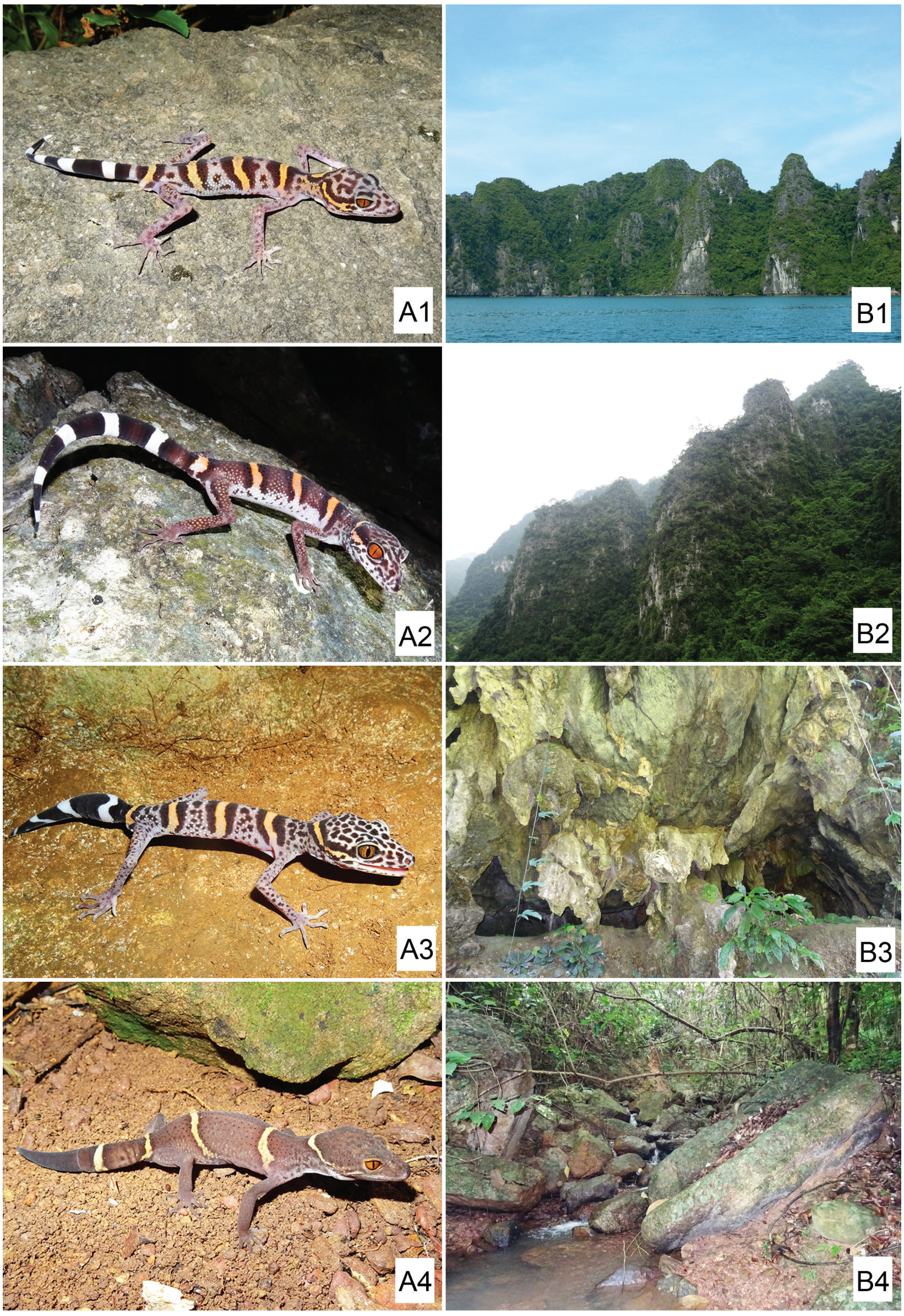

Figure 2. A1-A3. Photos of karst-adapted species (Goniurosaurus catbaensis, G. huuliensis, and G. luii, respectively), A4. Granite-stream-adapted species (G. lichtenfelderi), B1 - B3. Karst habitats of the luii group, B4. Granite-stream habitat of the lichtenfelderi group. Photos by Hai Ngoc Ngo. 
Table 1. Species and GenBank accession numbers of the sequenced specimens used herein.

\begin{tabular}{|c|c|c|c|c|}
\hline Species/Specimen & $16 \mathrm{~s}$ & cytb & CMOS & RAG1 \\
\hline Goniurosaurus araneus & AB308460 & & & \\
\hline G. araneus ECNU-V0008 & MT533259 & & & \\
\hline G. araneus JFBM15830 & & & HQ426537 & HQ426286 \\
\hline G. bawanglingensis BL-RBZ-021 & MH247190 & MH247201 & MH247212 & MH247223 \\
\hline G. bawanglingensis BL-RBZ-022 & MH247191 & MH247202 & MH247213 & MH247224 \\
\hline G. bawanglingensis BL-RBZ-023 & MH247192 & MH247203 & MH247214 & MH247225 \\
\hline G. bawanglingensis BL-RBZ-024 & МH247193 & MH247204 & MH247215 & MH247226 \\
\hline G. bawanglingensis SYS r002162 & MT995758 & MT995773 & & \\
\hline G. catbaensis G33 & MW741550 & MW650944 & & \\
\hline G. catbaensis G34 & MW741551 & MW650945 & & \\
\hline G. catbaensis G35 & & MW650946 & & \\
\hline G. catbaensis MHNG 2699.49 & EU499389 & & & \\
\hline G. gezhi ECNU-V0038 & MT533260 & & & \\
\hline G. gezhi ECNU-V0040 & MT533261 & & & \\
\hline G. gezhi ECNU-V0042 & MT533262 & & & \\
\hline G. gezhi ECNU-V0046 & MT533263 & & & \\
\hline G. gezhi ECNU-V0047 & MT533264 & & & \\
\hline G. gollum SYS r002420 & MT995784 & MT995787 & MW727559 & MW727594 \\
\hline G. gollum SYS r002421 & MT995785 & MT995788 & MW727560 & MW727595 \\
\hline G. gollum SYS r002422 & MT995786 & MT995789 & MW727561 & MW727596 \\
\hline G. hainanensis BL-RBZ-041 & MH247194 & MH247205 & MH247216 & MH247227 \\
\hline G. hainanensis BL-RBZ-042 & MH247195 & MH247206 & MH247217 & MH247228 \\
\hline G. hainanensis SYS r000349 & KC765080 & & & \\
\hline G. hainanensis JK1 & AB308458 & & & \\
\hline G. huuliensis Gohu & AB853453 & AB853479 & & \\
\hline G. huuliensis G21 & & MW650936 & & \\
\hline G. huuliensis G23 & & MW650937 & & \\
\hline G. huuliensis G24 & & MW650938 & & \\
\hline G. kadoorieorum ECNU-V0058 & MT533258 & & & \\
\hline G. kadoorieorum ECNU-V0060 & MT533265 & & & \\
\hline G. kadoorieorum ECNU-V0061 & MT533266 & & & \\
\hline G. kuroiwae Goku1 Northern Okinawa & AB853448 & AB853473 & & \\
\hline G. kuroiwae Goku2 Southern Okinawa & $\mathrm{AB} 853445$ & & & \\
\hline G. kuroiwae Goor1 Southern Okinawa & AB853446 & AB853467 & & \\
\hline G. kwanghua ECNU-V0003 & MK782788 & MK782782 & MK782776 & MK782770 \\
\hline G. kwanghua ECNU-V0004 & MK782789 & MK782783 & MK782777 & MK782771 \\
\hline G. kwanghua ECNU-V0005 & MK782790 & MK782784 & MK782778 & MK782772 \\
\hline G. kwangsiensis ECNU-V0009 & MK782786 & MK782780 & MK782774 & MK782768 \\
\hline G. liboensis SYS r000217 & KC900230 & & & \\
\hline G. lichtenfelderi ECNU-V0007 & MK782785 & MK782779 & MK782773 & MK782767 \\
\hline G. lichtenfelderi IEBR 3692 & JF799756 & & & \\
\hline G. luii ECNU-V0012 & MK782787 & MK782781 & MK782775 & MK782769 \\
\hline G. luii Golu2 & & & EF081254 & \\
\hline G. luii Golu3 & AB853452 & AB853478 & & \\
\hline G. luii SYSr 000255 & KC765083 & & & \\
\hline G. luii SYSr 000256 & KC765084 & & & \\
\hline G. luii ZFMK 87057 & EU499391 & & & \\
\hline G. luii TG00795 & & & & HQ426287 \\
\hline G. orientalis Goku3 & AB853446 & & & \\
\hline G. orientalis Goor2 & AB853443 & AB853461 & & \\
\hline G. orientalis Goor3 & & AB853462 & & \\
\hline G. sengokui Gose1 & AB853444 & $\mathrm{AB} 853463$ & & \\
\hline G. sengokui Gose2 & & $\mathrm{AB} 853464$ & & \\
\hline G. sengokui KUZ 62087 & & & HQ876393 & \\
\hline G. splendens Gosp1 & AB853451 & AB853477 & & \\
\hline G. splendens Gosp2 & AB853449 & & & \\
\hline G. splendens Gosp3 & $\mathrm{AB} 853450$ & & & \\
\hline
\end{tabular}




\begin{tabular}{|c|c|c|c|c|}
\hline Species/Specimen & $16 s$ & cytb & CMOS & RAG1 \\
\hline G. toyamai Goto1 & $\mathrm{AB} 853447$ & AB853468 & & \\
\hline G. toyamai Goto2 & & AB853469 & & \\
\hline G. varius SYS r002331 & MT995754 & MT995769 & MW727556 & MW727590 \\
\hline G. varius SYS r002332 & MT995755 & MT995770 & & \\
\hline G. varius SYS r002333 & MT995753 & MT995768 & & \\
\hline G. varius SYS r002362 & MT995756 & MT995771 & MW727557 & MW727592 \\
\hline G. varius SYS r002363 & MT995757 & MT995772 & MW727558 & MW727593 \\
\hline G. varius SYS r002485 & MW721828 & MW727532 & MW727562 & MW727597 \\
\hline G. varius SYS r002486 & MW721829 & MW727533 & MW727563 & MW727598 \\
\hline G. yamashinae Goya1 & $\mathrm{AB} 853442$ & $\mathrm{AB} 853460$ & & \\
\hline G. yamashinae Goya2 & AB853441 & AB853459 & & \\
\hline G. yamashinae Goya3 & & AB853458 & & \\
\hline G. yingdeensis Field number DYA01 & MW721830 & MW727534 & MW727574 & MW727605 \\
\hline G. yingdeensis Field number DYA02 & MW721831 & MW727535 & MW727575 & MW727606 \\
\hline G. yingdeensis Field number HS01 & MW721832 & MW727536 & MW727576 & MW727607 \\
\hline G. yingdeensis Field number HS02 & MW721833 & MW727537 & MW727577 & MW727608 \\
\hline G. yingdeensis Field number LT01 & MW721834 & MW727538 & MW727580 & MW727611 \\
\hline G. yingdeensis Field number LT02 & MW721835 & MW727539 & MW727581 & MW727612 \\
\hline G. yingdeensis SYS r000549 & KC765082 & & & \\
\hline G. yingdeensis SYS r000550 & KC900231 & & & \\
\hline G. yingdeensis SYS r001271 & MT995759 & MT995774 & MW727547 & \\
\hline G. yingdeensis SYS r001272 & MT995760 & MT995775 & MW727548 & \\
\hline G. yingdeensis SYS r001493 & MT995761 & MT995776 & MW727551 & \\
\hline G. yingdeensis SYS r0002115 & MT995762 & MT995777 & & \\
\hline G. zhelongi Field number HW01 & MW721838 & MW727540 & MW727578 & MW727609 \\
\hline G. zhelongi Field number HW02 & MW721839 & MW727541 & MW727579 & MW727610 \\
\hline G. zhelongi Field number MDA01 & MW721836 & MW727542 & MW727582 & MW727613 \\
\hline G. zhelongi Field number MDA02 & MW721837 & MW727543 & MW727583 & MW727614 \\
\hline G. zhelongi Field number TZ01 & MW721840 & MW727544 & MW727584 & MW727615 \\
\hline G. zhelongi Field number TZ02 & MW721841 & MW727545 & MW727585 & MW727616 \\
\hline G. zhelongi SYS r000816 & KJ423105 & MT995778 & MW727570 & \\
\hline G. zhelongi SYS r001491 & MT995763 & MT995779 & MW727549 & \\
\hline G. zhelongi SYS r001492 & MT995764 & MT995780 & MW727550 & \\
\hline G. zhelongi SYS r002108 & MT995765 & MT995781 & & \\
\hline G. zhoui BL-RBZ-001 & MH247196 & MH247207 & MH247218 & MH247229 \\
\hline G. zhoui BL-RBZ-004 & MH247197 & MH247208 & MH247219 & MH247230 \\
\hline G. zhoui BL-RBZ-006 & MH247198 & MH247209 & MH247220 & MH247231 \\
\hline G. zhoui BL-RBZ-007 & MH247199 & MH247210 & MH247221 & MH247232 \\
\hline G. zhoui BL-RBZ-008 & MH247200 & & & \\
\hline G. zhoui SYS r002213 & MT995766 & MT995782 & MW727553 & \\
\hline G. zhoui SYS r002214 & MT995767 & MT995783 & MW727554 & \\
\hline Eublepharis macularius & $\mathrm{AB} 853454$ & AB853480 & & \\
\hline
\end{tabular}

habitat preference coevolved with ecomorphology in near sympatric species of the luii and lichtenfelderi groups in Vietnam (Ngo et al. 2021; Figs. 1, 2).

\section{Materials and methods}

\section{Genetic data and phylogenetic analyses}

Genomic DNA was extracted from muscle tissue samples, using a DNA extraction kit from Tiangen Biotech (Beijing) Co., Ltd. Primers used for 16S were r16S-5L
(5'- GGTMMYGCCTGCCCAGTG -3') and 16Sbr-H (5'- CCGGTCTGAACTCAGATCACGT-3') (Palumbi et al. 1991), for cyt $b$ the primers were L14731 (5'- TGGTCTGAAAAACCATTGTTG-3') (Honda et al. 2014) and H15149m (5'- GCMCCTCAGAAKGATATTTGYCCTCA-3') (Chambers and MacAvoy 1999), for CMOS the primers were FU-F (5' - TTTGGTTCKGTCTACAAGGCTAC -3') and FU-R (5'- AGGGAACATCCAAAGTCTCCAAT -3') (Gamble et al., 2008), and for RAG1 the primers were R13 (5' - TCTGAATGGAAATTCAAGCTGTT -3') and R18 (5'- GATGCTGCCTCGGTCGGCCACCTTT -3') (Groth and Barrowclough 1999). The PCR procedure was performed with an initial denaturation at $94{ }^{\circ} \mathrm{C}$ for $5 \mathrm{~min}, 35$ cycles of $94{ }^{\circ} \mathrm{C}$ for $30 \mathrm{~s}$, $55^{\circ} \mathrm{C}$ for $30 \mathrm{~s}$ and $72{ }^{\circ} \mathrm{C}$ for $1 \mathrm{~min}$, followed by a final 
extension at $72{ }^{\circ} \mathrm{C}$ for $10 \mathrm{~min}$ (Liang et al. 2018). PCR products were purified with spin columns and then sequenced with forward primers using BigDye Terminator Cycle Sequencing Kit as per the guidelines on an ABI Prism 3730 automated DNA sequencer by Shanghai Majorbio Bio-pharm Technology Co., Ltd.

We constructed Maximum Likelihood (ML), Bayesian Inference (BI), and Bayesian Evolutionary Analysis by Sampling Trees (BEAST) phylogenetic trees using a concatenated data set composed of 3070 base pairs (bp) of the mitochondrial genes, $16 \mathrm{~S}$ (633 bp) and cyt $b$ (1075 bp), and the nuclear genes, CMOS (472 bp) and RAG1 (890), from 103 specimens of 23 species of Goniurosaurus with varying degrees of sequence coverage across the samples (Table 1). Concatenation followed the comparison of separate gene trees to confirm there were no major discordances. One species, Eublepharis macularius, served as an outgroup (Grismer 1988; Jonniaux and Kumazawa 2008) to root the trees. Sequence data and GenBank accession numbers are listed in Table 1.

A Maximum likelihood (ML) analysis partitioned by gene was implemented using the IQ-TREE webserver (Nguyen et al. 2015; Trifinopoulos et al. 2016) preceded by the selection of substitution models using TIM2 $+\mathrm{F}+\mathrm{I}+\mathrm{G} 4$ for $16 \mathrm{~S}$ and cyt $b$ and $\mathrm{HKY}+\mathrm{F}$ for $\mathrm{CMOS}$ and RAG1. To avoid over parameterization, protein coding genes were not partitioned by codon. One-thousand bootstrap pseudoreplicates via the ultrafast bootstrap (UFB: Hoang et al. 2018) approximation algorithm were employed, and nodes having UFB values of 95 and above were considered strongly supported (Minh et al. 2013). We considered nodes with values of 90-94 as well-supported. A Bayesian inference (BI) analysis was carried out in MrBayes 3.2.3. (Ronquist et al. 2012) on XSEDE using the CIPRES Science Gateway (Cyberinfrastructure for Phylogenetic Research; Miller et al. 2010) employing default priors and models of evolution that most closely approximated those selected by the BIC and used in the ML analysis. Two independent Markov chain Monte Carlo (MCMC) analyses for each data set were performed - each with four chains, three hot and one cold. The MCMC simulations ran for 100 million generations. Trees were sampled every 10,000 generations, and the first $10 \%$ of the trees from each run from each data set were discarded as burn-in. The parameter files from both runs were checked in Tracer v1.6 (Rambaut et al. 2014) to ensure that convergence and stationarity of all parameters had effective sample sizes (ESS) well-above above 200. Post-burn-in sampled trees from each respective run were combined and 50\% majority-rule consensus trees were constructed. Nodes with Bayesian posterior probabilities (BPP) of 0.95 and above were considered highly supported (Huelsenbeck et al. 2001; Wilcox et al. 2002). We considered nodes with values of $0.90-0.94$ as well-supported.

An input file was constructed in Bayesian Evolutionary Analysis Utility (BEAUti) v. 2.4.6 using a relaxed lognormal clock with unlinked site models, linked trees and clock models, and a Yule prior and run in BEAST on CIPRES (Cyberinfrastructure for Phylogenetic Research;
Miller et al. 2010). bModelTest was used to numerically integrate over the uncertainty of substitution models of each gene while simultaneously estimating phylogeny using Markov chain Monte Carlo (MCMC). MCMC chains were run for 100,000,000 generations and logged every 10,000 generations. The BEAST log file was visualized in Tracer v. 1.6.0 (Rambaut et al. 2014) to ensure effective sample sizes (ESS) were well-above 200 for all parameters. A Maximum clade credibility tree using mean heights at the nodes was generated using TreeAnnotator v.1.8.0 (Rambaut and Drummond 2014) with a burn-in of 1000 trees $(10 \%)$. Nodes with BPPs of 0.95 and above were considered strongly supported (Huelsenbeck et al. 2001; Wilcox et al. 2002). We considered nodes with values of 0.90-0.94 as well-supported.

\section{Ancestral state reconstruction}

The BEAST tree was converted to newick format and pruned using the drop.tip() command (Paradis and Schliep 2018) in the R package ape [v.3.4.3] to include only the earliest diverged individual of each species. Habitat preference (karst or non-karst; see below) was mapped onto the tree using SCM implemented in the R package Phytools (Revell 2012) in order to derive probability estimates of the ancestral states at each node. A transition rate matrix was identified that best fit the data by comparing the corrected Akaike Information Criterion (AICc) values in the R package ape (Paradis and Schilep 2018). Three transition rate models were considered: a 2-parameter model having different rates for every transition type (the ARD model); a single-parameter model with equal forward and reverse rates between states (the symmetrical rates SYM model); and a single rate parameter model that assumes equal rates among all transitions (ER). Lastly, an MCMC approach was used to sample the most probable 1000 trait histories from the posterior using the make.simmap () command and then summarized them using the summary() command.

The coding of habitat preference for each species was determined from the literature and field observations of the authors (Table 2). A species' habitat preference was coded as "karst" if it had a strong association with karstic habitats. Many such species may range into forested areas or even other rock types (granite or volcanic) if nearby but their densities are much greater in karstic areas. A species was coded as "non-karst" if detected only in forested areas or forested areas with other rock types (e.g. granite). These species never show any strong preference for karstic microhabitats even if such habitats exist within their range.

\section{Morphological data and analyses}

An ecomorphological analysis was conducted using four of the five recorded species from Vietnam (Grismer et al. 1999; Vu et al. 2006; Orlov et al. 2008; Ziegler et al. 2008; Nguyen et al. 2009; Nguyen 2011; Orlov et al. 
Table 2. Habitat preferences of the species of Goniurosaurus.

\begin{tabular}{|c|c|c|c|}
\hline Species & $1^{\circ}$ habitat & $2^{\circ}$ habitat & Source \\
\hline \multicolumn{4}{|l|}{ kuroiwae group } \\
\hline G. splendens & karst & forest & Nakamura and Ueno (1963), H. Ota pers. comm., L. Grismer pers. obs. \\
\hline G. toyamai & forest & & H. Ota pers. comm. \\
\hline G. kuroiwae North & forest & & H. Ota pers. comm., L. Grismer pers. obs., \\
\hline G. kuroiwae South & karst & forest & Nakamura and Ueno (1963), H. Ota pers. comm., L. Grismer pers. obs. \\
\hline G. yamashinae & karst & forest & H. Ota pers. comm., L. Grismer pers. obs., \\
\hline G. sengokui & karst & forest & Werner et al. (2004), H. Ota pers. comm. \\
\hline G. orientalis & karst & & H. Ota pers. comm. \\
\hline \multicolumn{4}{|l|}{ yingdeensis group } \\
\hline G. gollum & karst & & Qi et al. (2020a) \\
\hline G. yingdeensis & karst & granite & Wang et al. (2010), S. Qi pers. obs. \\
\hline G. zhelongi & karst & granite & S. Qi, pers. obs., Wang et al. (2014) \\
\hline G. varius & karst & & Qi et al. (2020b) \\
\hline \multicolumn{4}{|l|}{ lichtenfelderi group } \\
\hline G. bawanglingensis & granite & karst & Grismer et al. (2002), Orlov et al. (2008) \\
\hline G. zhoui & karst & granite & Zhou et al. (2018), S. Qi pers. obs. \\
\hline G. kwanghua & karst & granite & Zhu et al. (2020) \\
\hline G. lichtenfelderi & granite & & Orlov et al. (2008) \\
\hline G. hainanensis & granite & volcanic & S. Qi pers. obs., L. Grismer pers. obs. \\
\hline \multicolumn{4}{|l|}{ luii group } \\
\hline G. catbaensis & karst & & Ziegler et al. (2008), Ngo et al. (2019a) \\
\hline G. gezhi & karst & & Zhu et al. (2020) \\
\hline G. araneus & karst & & Grismer et al. (1999) \\
\hline G. kadoorieorum & karst & & Yang and Chan (2015) \\
\hline G. huuliensis & karst & & Orlov et al. (2008) \\
\hline G. luii & karst & & Grismer et al. (1999), Vu et al. (2006) \\
\hline G. liboensis & karst & & Wang et al. (2013) \\
\hline G. kwangsiensis & karst & & Yang and Chan (2015) \\
\hline
\end{tabular}

2020) for which there existed a substantially large morphometric data set (Ngo et al. 2021): the karst-adapted $G$. catbaensis Ziegler, Nguyen, Schmitz, Stenke, and Rösler, 2008, G. huuliensis Orlov, Ryabov, Nguyen, Nguyen, and Ho, 2008, and G. luii Grismer, Viets, and Boyle, 1999 of the luii group and the granite stream-adapted G. lichtenfelderi (Mocquard, 1897) of the lichtenfelderi group (Figs. 1, 2). A total of 486 live individuals and 54 museum specimens of four species were examined for morphological data, comprising 194 individuals of $G$. catbaensis (21 juveniles, 93 females, and 80 males), 80 individuals of $G$. huuliensis (two juveniles, 46 females, and 32 males), and 88 individuals of $G$. luii (11 juveniles, 43 females, and 34 males) of the luii species group and 178 individuals of $G$. lichtenfelderi (14 juveniles, 72 females, and 92 males) of the lichtenfelderi group.

Measurements were taken with dial calipers to the nearest $0.1 \mathrm{~mm}$ on the right side of each individual. Abbreviations are as follows: snout-vent length (SVL), from tip of snout to vent; axilla to groin length (AG), from posterior edge of forelimb insertion to anterior edge of hind limb insertion; maximum body width (BW), greatest width of torso, taken at level of midbody; maximum body height $(\mathrm{BH})$, from dorsal surface of body to belly; internarial distance (ID), distance between nares; head length (HL), from the tip of snout to posterior edge of occiput; maximum head width $(\mathrm{HW})$; cheek height $(\mathrm{CH})$, from posterior edge of labial to top of head at parietal region; interorbital distance (IO), distance between posteriormost points of eyes; diameter of auditory meatus (AD); snout to eye distance (SL), measured from tip of snout to anteriormost point of eye; diameter of eye (ED), greatest diameter of eye; eye to ear distance (EE), from posterior margin of eye to posterior margin of ear; forelimb length (FLL), from axilla to the tip of the fourth finger; hind limb length (HLL), from groin to the tip of the fourth toe. To remove potential effects of allometry, size was adjusted using the following equation: $X_{\text {adj }}=\log (X)-\beta[\log (\mathrm{SVL}$ )$\left.-\log \left(\mathrm{SVL}_{\text {mean }}\right)\right]$, where $\mathrm{X}_{\mathrm{adj}}=$ adjusted value; $\mathrm{X}=$ measured value; $\beta=$ unstandardized regression coefficient for each population; and $\mathrm{SVL}_{\text {mean }}=$ overall average $\mathrm{SVL}$ of all populations (Thorpe 1975, 1983; Turan 1999; Lleonart et al. 2000) - accessable in the R package GroupStruct (available at https://github.com/chankinonn/GroupStruct). The morphometrics of each species were adjusted separately and then concatenated so as not to conflate intra- with interspecific variation (Reists 1986). All data were then scaled to their standard deviation to insure they were analyzed on the basis of correlation and not covariance and were log-transformed to insure they were normally distributed.

An analysis of variance (ANOVA) was performed on a data set coded for species to search for the presence of statistically significant mean differences $(p<0.05)$ 


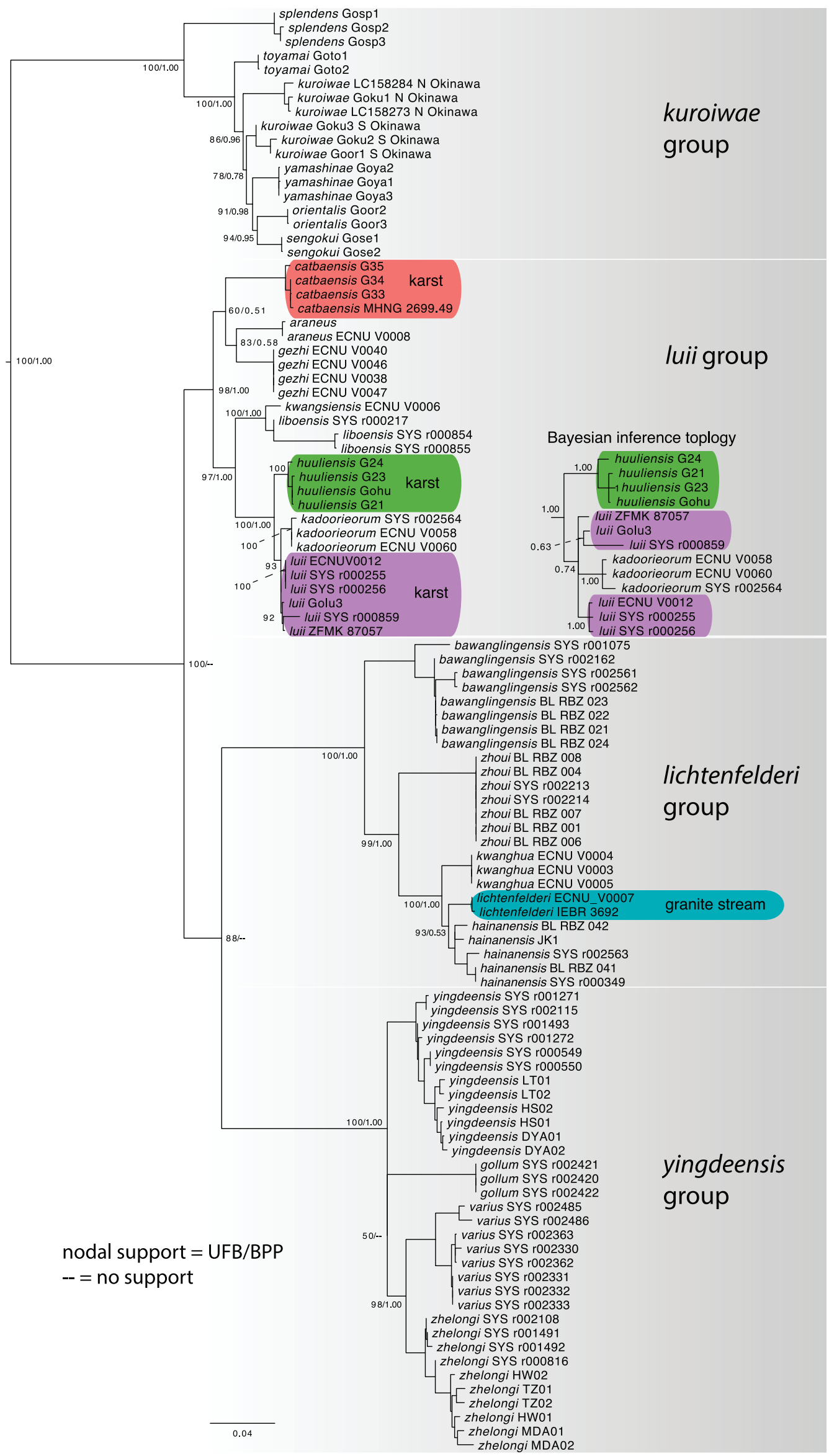

Figure 3. Mito-nuclear maximum likelihood topology with ultrafast bootstrap values (UFB) and Bayesian posterior probabilities (BPP) at the nodes. All species except Goniurosaurus luii had strong nodal support (100/1.00) for their monophyly. The inset in the luii species group is a section of the BI analysis showing the non-monophyly of G. luii with respect to G. kadoorieorum. Colored species are those used in the ecomorphological analyses. 


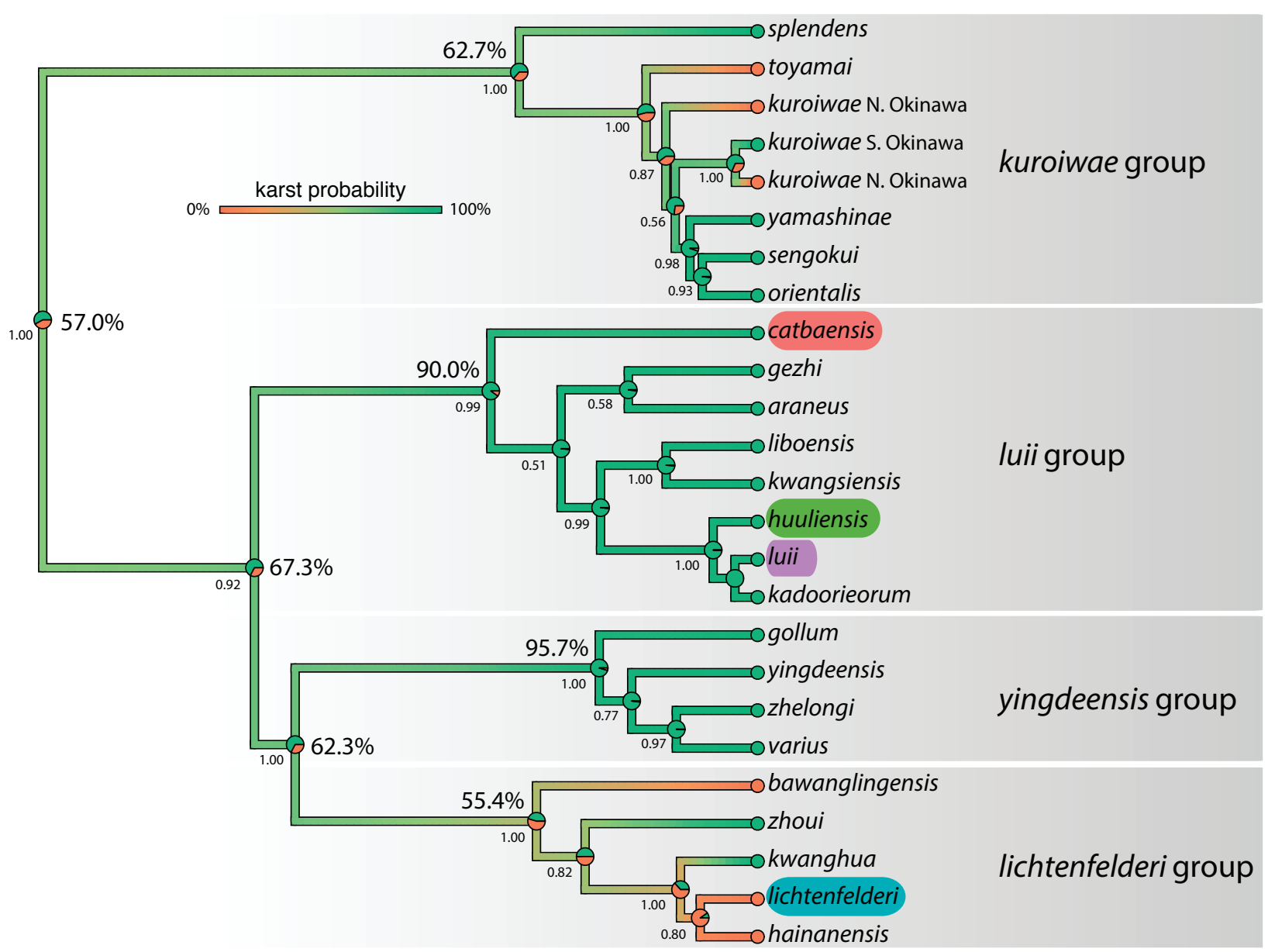

Figure 4. Stochastic character map of karst and non-karst habitat preferences on a BEAST topology. Percentages at the nodes are the probability of the ancestral habitat preference. Numbers at the nodes are BPP values. Colored species are those used in the ecomorphological analyses.

among characters across the selected subset of species in the luii and lichtenfelderi groups. Character means bearing statistical differences among species were subjected to a TukeyHSD test to ascertain which species pairs differed significantly from each other for those particular characters. A Student $t$-test was also performed on a second data set coded for only habitat preference (karst versus non-karst) to search for the presence of statistically significant mean differences $(p<0.05)$ among the same subsets of species coded for habitat. Violin plots with inserted boxplots were generated in order to visualize the range, frequency, mean, $50 \%$ quartile, and degree of differences between the dependent variables for both data sets bearing statistically different mean values.

The morphospatial clustering of the two separate data sets (species and habitat preference) were visualized using principal component analysis (PCA) along the ordination of the first two principal components (PC) using the Adegenet package in R (Jombart et al. 2010) and implemented by the $\operatorname{prcomp}()$ command. The data were log-transformed prior to analysis in order to normalize their distribution so as to ensure characters with very large or very low values could not over-leverage the results owing to intervariable nonlinearity. All statistical analyses were performed using R.3.1.2 (R Core Team 2018).

\section{Results}

\section{Phylogenetic relationships}

The ML, BI, and BEAST analyses recovered strong nodal support (UFB 98-100/BPP 1.00) for the monophyly of all four species groups with the kuroiwae group being the strongly supported (100/1.00) sister group to the remaining three groups (Fig. 3). The ML analysis weakly recovered (88) the lichtenfelderi and yingdeensis groups as sister lineages but the BEAST analysis recovered this relationship with strong support (1.00; Fig. 4). The BI analysis recovered the luii and yingdeensis groups as sister lineages, although the support is so low (0.51), the three groups effectively form a polytomy. The ML and $\mathrm{BI}$ analyses recovered the identical inter-specific relationships within the species groups but discordant relationships with the BEAST analysis regarding the luii group. The ML and BI analyses recovered a poorly supported ( $G$. catbaensis ( $G$. araneus, G. gezhi)) clade but the BEAST analysis recovered G. catbaensis as the strongly supported (0.99) sister species to the remainder of the luii group species (Figs. 3, 4, respectively). All analyses recovered a polyphyletic Goniurosaurus luii with respect to G. kadoorieorum (not shown in the pruned tree of Fig. 4). 
Table 3. Difference, lower and upper ranges, and adjusted $p$ values of statistically significant mean differences between species pairs for each character based on ANOVA and subsequent TukeyHSD analyses.

\begin{tabular}{|c|c|c|c|c|}
\hline axilla-groin (AG) & difference & lower range & upper range & $p$ adjusted \\
\hline huuliensis-catbaensis & 0.095633573 & 0.072292064 & 0.118975082 & $3.37 \mathrm{E}-10$ \\
\hline lichtenfelderi-catbaensis & -0.075967576 & -0.094200659 & -0.057734493 & $3.37 \mathrm{E}-10$ \\
\hline luii-catbaensis & -0.029676257 & -0.05225407 & -0.007098445 & 0.004206065 \\
\hline lichtenfelderi-huuliensis & -0.171601149 & -0.195246969 & -0.14795533 & $3.37 \mathrm{E}-10$ \\
\hline luii-huuliensis & -0.12530983 & -0.152447204 & -0.098172456 & $3.37 \mathrm{E}-10$ \\
\hline luii-lichtenfelderi & 0.046291319 & 0.023399042 & 0.069183596 & $1.60 \mathrm{E}-06$ \\
\hline \multicolumn{5}{|l|}{ body width (BW) } \\
\hline huuliensis-catbaensis & 0.106179184 & 0.066412755 & 0.145945613 & $4.37 \mathrm{E}-10$ \\
\hline lichtenfelderi-huuliensis & -0.083314667 & -0.123599543 & -0.043029791 & 8.67E-07 \\
\hline luii-huuliensis & -0.121548632 & -0.167781995 & -0.075315269 & $5.34 \mathrm{E}-10$ \\
\hline \multicolumn{5}{|l|}{ body height (BH) } \\
\hline huuliensis-catbaensis & 0.094637915 & 0.046801122 & 0.142474708 & $2.84 \mathrm{E}-06$ \\
\hline lichtenfelderi-huuliensis & -0.07317021 & -0.121630666 & -0.024709755 & 0.000647886 \\
\hline luii-huuliensis & -0.125013692 & -0.180629845 & -0.069397539 & $7.11 \mathrm{E}-08$ \\
\hline luii-lichtenfelderi & -0.051843482 & -0.098759605 & -0.004927359 & 0.02359844 \\
\hline \multicolumn{5}{|l|}{ internarial distance (ID) } \\
\hline lichtenfelderi-catbaensis & -0.082396274 & -0.105742691 & -0.059049857 & $3.37 \mathrm{E}-10$ \\
\hline luii-catbaensis & -0.076638786 & -0.105548379 & -0.047729192 & $4.74 \mathrm{E}-10$ \\
\hline lichtenfelderi-huuliensis & -0.096677642 & -0.126954757 & -0.066400527 & $3.37 \mathrm{E}-10$ \\
\hline luii-huuliensis & -0.090920154 & -0.125668004 & -0.056172303 & $5.78 \mathrm{E}-10$ \\
\hline \multicolumn{5}{|l|}{ head length (HL) } \\
\hline huuliensis-catbaensis & 0.075818967 & 0.058801575 & 0.092836359 & $3.37 \mathrm{E}-10$ \\
\hline lichtenfelderi-catbaensis & -0.162875997 & -0.176169033 & -0.149582961 & $3.37 \mathrm{E}-10$ \\
\hline luii-catbaensis & -0.029098886 & -0.045559496 & -0.012638276 & $3.82 \mathrm{E}-05$ \\
\hline lichtenfelderi-huuliensis & -0.238694964 & -0.255934217 & -0.221455712 & $3.37 \mathrm{E}-10$ \\
\hline luii-huuliensis & -0.104917853 & -0.124702663 & -0.085133043 & $3.37 \mathrm{E}-10$ \\
\hline luii-lichtenfelderi & 0.133777111 & 0.117087238 & 0.150466985 & $3.37 \mathrm{E}-10$ \\
\hline \multicolumn{5}{|l|}{ head width (HW) } \\
\hline huuliensis-catbaensis & 0.036775074 & 0.019138869 & 0.05441128 & $6.89 \mathrm{E}-07$ \\
\hline lichtenfelderi-catbaensis & -0.158637831 & -0.172414249 & -0.144861413 & $3.37 \mathrm{E}-10$ \\
\hline luii-catbaensis & -0.065002064 & -0.082061241 & -0.047942887 & $3.37 \mathrm{E}-10$ \\
\hline lichtenfelderi-huuliensis & -0.195412905 & -0.213279039 & -0.177546772 & $3.37 \mathrm{E}-10$ \\
\hline luii-huuliensis & -0.101777138 & -0.122281395 & -0.081272881 & $3.37 \mathrm{E}-10$ \\
\hline luii-lichtenfelderi & 0.093635767 & 0.07633899 & 0.110932545 & $3.37 \mathrm{E}-10$ \\
\hline \multicolumn{5}{|l|}{\begin{tabular}{|l|} 
head height (HH) \\
\end{tabular}} \\
\hline huuliensis-catbaensis & 0.108413032 & 0.073172094 & 0.143653969 & 3.37E-10 \\
\hline lichtenfelderi-catbaensis & -0.032237965 & -0.059766217 & -0.004709713 & 0.014142658 \\
\hline lichtenfelderi-huuliensis & -0.140650997 & -0.176351381 & -0.104950613 & 3.37E-10 \\
\hline luii-huuliensis & -0.14002168 & -0.180993602 & -0.099049757 & $3.37 \mathrm{E}-10$ \\
\hline \multicolumn{5}{|l|}{ cheek height $(\mathrm{CH})$} \\
\hline huuliensis-catbaensis & 0.069595379 & 0.028246161 & 0.110944597 & 0.000101199 \\
\hline lichtenfelderi-catbaensis & -0.14807373 & -0.180373429 & -0.11577403 & $3.37 \mathrm{E}-10$ \\
\hline luii-catbaensis & -0.057345812 & -0.09734215 & -0.017349473 & 0.001381599 \\
\hline lichtenfelderi-huuliensis & -0.217669109 & -0.259557409 & -0.175780808 & $3.37 \mathrm{E}-10$ \\
\hline luii-huuliensis & -0.126941191 & -0.175014741 & -0.078867641 & $5.00 \mathrm{E}-10$ \\
\hline luii-lichtenfelderi & 0.090727918 & 0.050174509 & 0.131281326 & $8.27 \mathrm{E}-08$ \\
\hline \multicolumn{5}{|l|}{ interorbital distance (ID) } \\
\hline huuliensis-catbaensis & 0.05692565 & 0.034698839 & 0.079152461 & $9.29 \mathrm{E}-10$ \\
\hline lichtenfelderi-catbaensis & -0.211451872 & -0.228814215 & -0.194089528 & $3.37 \mathrm{E}-10$ \\
\hline luii-catbaensis & -0.03636425 & -0.057863835 & -0.014864664 & $9.22 \mathrm{E}-05$ \\
\hline lichtenfelderi-huuliensis & -0.268377522 & -0.29089411 & -0.245860933 & $3.37 \mathrm{E}-10$ \\
\hline luii-huuliensis & -0.093289899 & -0.1191313 & -0.067448499 & $3.37 \mathrm{E}-10$ \\
\hline luii-lichtenfelderi & 0.175087622 & 0.15328859 & 0.196886655 & $3.37 \mathrm{E}-10$ \\
\hline \multicolumn{5}{|l|}{\begin{tabular}{|l|} 
snout length (SL) \\
\end{tabular}} \\
\hline huuliensis-catbaensis & 0.108547374 & 0.083797596 & 0.133297152 & $3.37 \mathrm{E}-10$ \\
\hline
\end{tabular}




\begin{tabular}{|c|c|c|c|c|}
\hline lichtenfelderi-catbaensis & -0.20706889 & -0.226402034 & -0.187735746 & $3.37 \mathrm{E}-10$ \\
\hline lichtenfelderi-huuliensis & -0.315616264 & -0.340688712 & -0.290543816 & $3.37 \mathrm{E}-10$ \\
\hline luii-huuliensis & -0.125435452 & -0.154210112 & -0.096660792 & $3.37 \mathrm{E}-10$ \\
\hline luii-lichtenfelderi & 0.190180812 & 0.16590737 & 0.214454254 & $3.37 \mathrm{E}-10$ \\
\hline \multicolumn{5}{|l|}{ ear diameter (ED) } \\
\hline huuliensis-catbaensis & -0.137477526 & -0.199198043 & -0.075757008 & $9.51 \mathrm{E}-08$ \\
\hline lichtenfelderi-catbaensis & -0.338691314 & -0.386903935 & -0.290478693 & $3.37 \mathrm{E}-10$ \\
\hline luii-catbaensis & -0.365692271 & -0.425393393 & -0.305991149 & $3.37 \mathrm{E}-10$ \\
\hline lichtenfelderi-huuliensis & -0.201213788 & -0.263738975 & -0.138688602 & $3.37 \mathrm{E}-10$ \\
\hline luii-huuliensis & -0.228214745 & -0.299972435 & -0.156457055 & $3.37 \mathrm{E}-10$ \\
\hline \multicolumn{5}{|l|}{ eye to ear distance (EE) } \\
\hline huuliensis-catbaensis & 0.085091637 & 0.059731157 & 0.110452117 & $3.37 \mathrm{E}-10$ \\
\hline lichtenfelderi-huuliensis & -0.06878479 & -0.094475902 & -0.043093678 & $4.25 \mathrm{E}-10$ \\
\hline luii-huuliensis & -0.101777804 & -0.131262479 & -0.072293128 & $3.37 \mathrm{E}-10$ \\
\hline luii-lichtenfelderi & -0.032993014 & -0.057865404 & -0.008120623 & 0.00377334 \\
\hline \multicolumn{5}{|l|}{ eye diameter (ED) } \\
\hline huuliensis-catbaensis & 0.085091637 & 0.059731157 & 0.110452117 & $3.37 \mathrm{E}-10$ \\
\hline lichtenfelderi-huuliensis & -0.06878479 & -0.094475902 & -0.043093678 & $4.25 \mathrm{E}-10$ \\
\hline luii-huuliensis & -0.101777804 & -0.131262479 & -0.072293128 & $3.37 \mathrm{E}-10$ \\
\hline luii-lichtenfelderi & -0.032993014 & -0.057865404 & -0.008120623 & 0.00377334 \\
\hline \multicolumn{5}{|l|}{ forelimb length (FLL) } \\
\hline huuliensis-catbaensis & -0.137477526 & -0.199198043 & -0.075757008 & $9.51 \mathrm{E}-08$ \\
\hline lichtenfelderi-catbaensis & -0.338691314 & -0.386903935 & -0.290478693 & $3.37 \mathrm{E}-10$ \\
\hline luii-catbaensis & -0.365692271 & -0.425393393 & -0.305991149 & $3.37 \mathrm{E}-10$ \\
\hline lichtenfelderi-huuliensis & -0.201213788 & -0.263738975 & -0.138688602 & $3.37 \mathrm{E}-10$ \\
\hline luii-huuliensis & -0.228214745 & -0.299972435 & -0.156457055 & $3.37 \mathrm{E}-10$ \\
\hline \multicolumn{5}{|l|}{ hindlimb length (HLL) } \\
\hline huuliensis-catbaensis & -0.137477526 & -0.199198043 & -0.075757008 & $9.51 \mathrm{E}-08$ \\
\hline
\end{tabular}

The mito-nuclear data set of Liang et al. (2018) differed from all the above analyses in that their ML and BI analyses (79/0.99) placed the yingdeensis group as the sister group to a sister lineage comprised of the luii group and lichtenfelderi group (87/1.00).

\section{Ancestral state reconstruction}

The AICc scores for the three transition rate models of the SCM analysis were ARD = 34.547134 and SYM and $\mathrm{ER}=32.099451$. The SCM analysis using either the SYM or ER model suggests that a karst habitat preference is the most probable ancestral condition for Goniurosaurus (57.0\% probability), the kuroiwae group $(62.7 \%)$, the luii group (90.0\%), and the yingdeensis group (95.7\%; Fig. 4). The probable ancestral condition for the lichtenfelderi group is non-karst (55.4\%). The karst habitat preference of G. kwanghua and G. zhoui of the lichtenfelderi group is considered to have evolved independently given that the ancestral condition of the lichtenfelderi group and that of the most recent common ancestor of the sister species $G$. lichtenfelderi and G. hainanensis was not karst-adapted (Fig. 4).

\section{Ecomorphology}

In both the species and habitat preference PCA analyses, $\mathrm{PC} 1$ accounted for $49.1 \%$ of the variation in the data set and loaded most heavily for limb length (FLL and HLL), snout length (SL), eye diameter (ED), interorbital distance (IO), head width (HW), and head length (HL). PC2 accounted for an additional $13.3 \%$ of the variation and loaded most heavily for body width (BW) and body height (BH) (Figs. 5, 6; Table 4).

The PCA analysis of the karst-adapted Goniurosaurus catbaensis, G. huuliensis, and G. luii of the luii group demonstrates that their body shapes greatly overlap in morphospace despite there being several slight, but statistically significant mean differences among them (Fig. 5; Table 3). Additionally, none of the plots of the karst-adapted species overlap with that of the granite stream-adapted species $G$. lichtenfelderi along the ordination of PC1.

The PCA analysis using habitat preference as the dependent variable among the four species, showed that the karst-adapted and granite-stream-adapted species plot separately as before along taxonomic lines and that collectively, the former have significantly longer axilla-groin lengths (AG); longer, wider, and thicker heads (HL, HW, and $\mathrm{CH}$ ); longer snouts (SL); longer limbs (FLL and HLL); wider interorbital distances (IO); larger eyes (ED) and larger ear openings (AD) (Fig. 6). Many of these characters-longer head and snout, larger eyes, longer trunk, longer limbs-occur in many other distantly related karst-adapted species of Cyrtodactylus (Grismer et al. 2016a, 2020b; Kaatz et al. 2021; Nielsen and Oliver 2017), indicating that these are convergent adaptions to a karstic life style within and between the gekkotan families. 


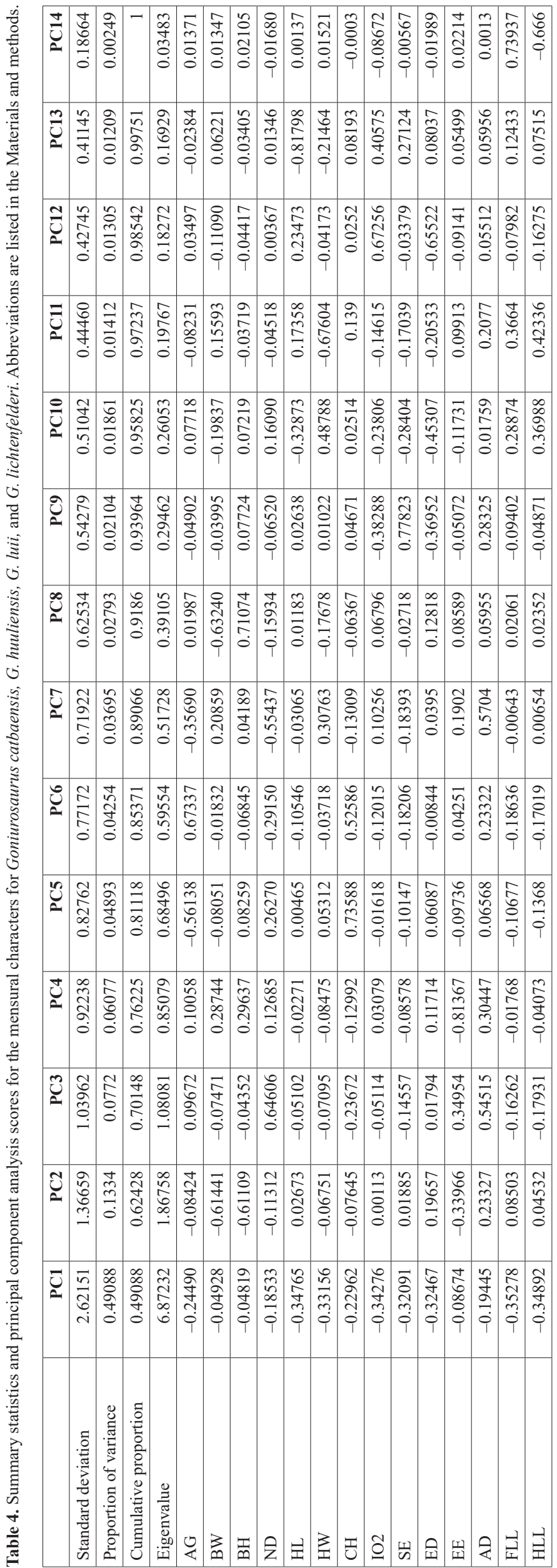

\section{Discussion}

Geckos in general are particularly well-adapted to karstic landscapes (see Luu et al. 2016; Grismer et al. 2014, 2020a, 2021 and references therein; Google Scholar search using key words "karst" and "Gekkonidae") and Goniurosaurus is no exception, being that 19 of its 23 species (83\%) occupy karstic habitats (Grismer et al. 1994, 1999; Orlov et al. 2008; Ziegler et al. 2008; Yang and Chan 2015; Honda and Ota 2017; Zhou et al. 2018; Ngo et al. 2019a; Qi et al. 2020a, 2020b; Zhu et al. 2020a, 2020b). It is clear that karstic landscapes have played a significant role in the evolution and diversification of Goniurosaurus being that it is the probable ancestral habitat preference for the genus and three of the four species groups. Even the ancestor of the nonkarst adapted ancestor of the lichtenfelderi group was karst-adapted (Fig. 4). Furthermore, within the species groups, the limited data herein would suggest that the karst-adapted species are specialized, range-restricted endemics (Grismer et al. 1994, 1999; Orlov et al. 2008; Ziegler et al. 2008; Yang and Chan 2015; Honda and Ota 2017; Zhou et al. 2018; Ngo et al. 2019a; Qi et al. 2020a, 2020b; Zhu et al. 2020a, 2020b). With the exception of G. lichtenfelderi, all the non-karst-adapted species are restricted to islands in the Ryukyu Archipelago (kuroiwae group) or Hainan Island (lichtenfelderi group). It may be that the absence of competition and/or predators in these insular habitats widened the fundamental niches of their ancestors and allowed some species to become more generalized in their habitat preference, which should be tested using new techniques combining phylogenetic history, character evolution, and ecological reconstruction programs.

\section{Systematics of the luii group}

The ML and BI analyses of Liang et al. (2018) and the BEAST analysis herein (Fig. 4) recovered Goniurosaurus catbaensis as the strongly supported sister species to the remainder of the luii group. Whereas the ML and BI analysis herein, recovered $G$. catbaensis as the very poorly supported $(60 / 0.51)$ sister species of the $G$. araneus plus $G$. gezhi clade (Fig. 3). Given that three of the five analyses strongly supported the former relationship and two analyses poorly supported the latter, we prefer the placement of G. catbaensis as the sister species to the remainder of the luii group (Fig. 4). Given the very low nodal support of the latter, it essentially renders that portion of the tree a polytomy and as such, does not effectively contradict the strongly supported sister species position of $G$. catbaensis in the other trees.

Goniurosaurus kadoorieorum of the luii group (represented by only $16 \mathrm{~S}$ ) is nested within G. luii in 


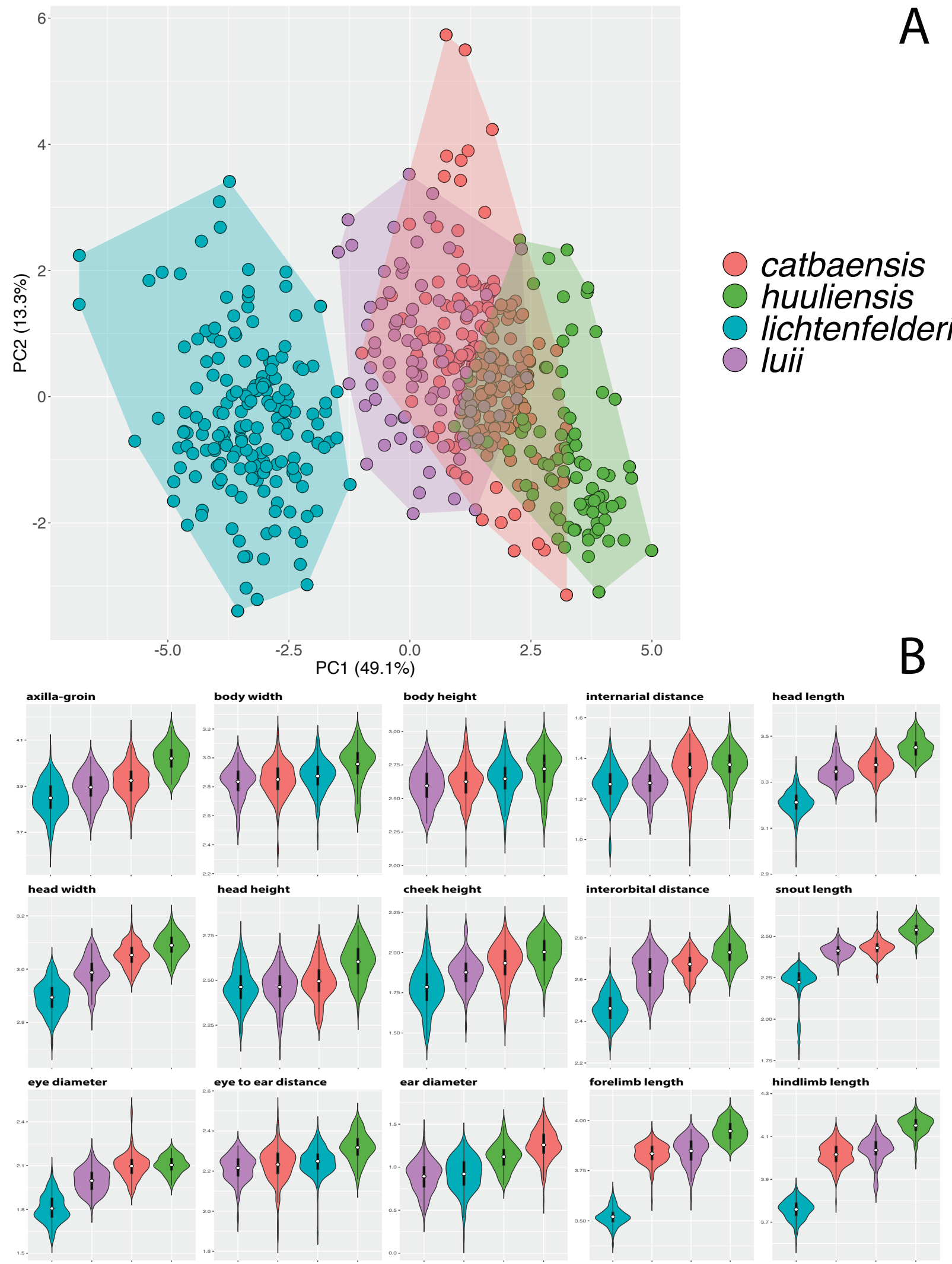

Figure 5. A. Principal component analysis of the karst-adapted species G. catbaensis, G. huuliensis, and G. luii of the luii group and the granite-stream-adapted G. lichtenfelderi of the lichtenfelderi group. B. Violin plots overlain with box plots showing the range, frequency, mean (white dot), and 50\% quartile (black rectangle) of the size-adjusted morphometric characters.

both the ML and BI analyses, rendering G. luii polyphyletic (Fig. 3). The same relationship was recovered in the $16 \mathrm{~S}$ phylogeny of Zhu et al. (2020a). This, and the lack of diagnostic characters separating G. kadoorieorum from
G. luii (Yang and Chan 2015; Ngo et al. 2016), indicates the two species should be considered conspecific and as such, G. kadoorieorum Yang and Chan, 2015 is relegated here to a junior synonym of $G$. luii Grismer, Viets, and 

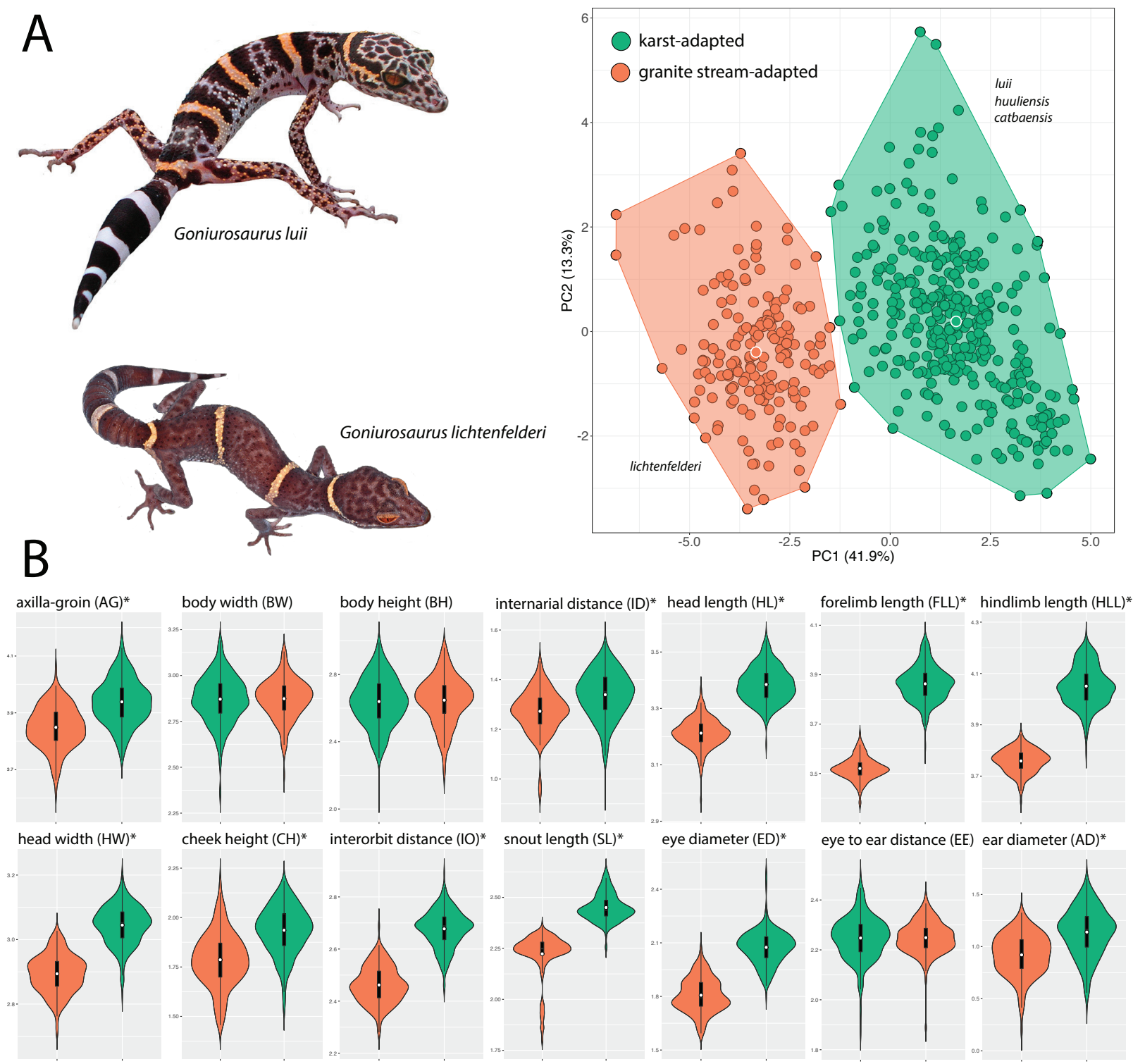

Figure 6. A. Principal component analysis using karst habitat preference and granite stream habitat preference as the dependent variables for G. catbaensis, G. huuliensis, and G. luii of the luii group and G. lichtenfelderi of the lichtenfelderi group. B. Violin plots overlain with box plots showing the range, frequency, mean (white dot), and 50\% quartile (black rectangle) of the size-adjusted morphometric characters. Asterisks denote characters bearing statistically significant mean differences between the karst and granite-stream-adapted species based on student $t$-tests. Upper photo from Vuu et al. (2008). Lower photo from Hai Ngoc Ngo.

Boyle, 1999. In all analyses, G. huuliensis is consistently recovered as the sister species to G. luii sensu lato and its species status is not questioned (Figs. 3, 4).

\section{Conservation}

Wide-ranging more inclusive studies pertaining to ecosystems management are becoming commonplace in light of climate change and widespread habitat destruction. Such studies reconcile data from a broad range of disciplines in order to address issues that may bear on ecosystems management. Foundational to many of these studies is a basic understanding of species ecology and habitat preference-correlated here with ecomorphology (Cabral et al. 2009; Harfoot et al. 2014). Baseline information on habitat and microhabitat requirements of any species are paramount to understanding how they interact with, and navigate through, their environment (e.g. Grant and Grant 2008; Greene 2005; Losos 2010) and as such, the contextualization of ecosystem management may ultimately turn on these simple points (Meiri 2018; Sinervo et al. 2010).

Integrating the phylogenetic patterns of biodiversity and the morphological adaptations of habitat preference that, in part, underpin species radiations, can fundamentally contribute to conservation management programs (Grismer et al. 2020a, 2021; Erwin 1991; Vane-Wright et al. 1991; Williams et al. 1991; Vázquez and Gittleman 1998; Moritz et al. 2000; Forest et al. 2007; Sgro et al. 2010; Harvey et al. 2011; Rolland et al. 2012; Winter et al. 2012; Shaffer et al. 2015; Beaumont and Wang 2019; Fay et al. 2019; Holderegger et al. 2019)—especially in the karstic regions of northern Vietnam where anthropogenic impact is degrading the habitat and reducing the 
density of localized populations of Goniurosaurus (Ngo et al. 2019b). Northern Vietnam and many of its offshore islands in the Gulf of Tonkin, harbor large areas of fragmented karstic habitats scattered across their landscapes (Cerrano et al. 2006; Do 2001, 2014; Luo et al. 2016; Ngo et al. 2019a) that are inhabited by an exceptionally large number of endemic plants and animals (Do 2001; Sterling et al. 2006; Clements et al. 2008; Luo et al. 2016; von Oheimb et al. 2017). The obligate restriction of many species to fragmented karstic environments - such as all species of the luii and yingdeensis groups - functionally transforms these environments into habitat islands (Clements et al. 2006, 2008; von Oheimb et al. 2017), which in some cases, bear an unprecedented degree of range-restricted endemism (e.g. Sgro et al 2012; Harvey et al. 2011; Grismer et al. 2018a, 2021).

Unfortunately, Goniurosaurus species are particularly attractive (Fig. 2) and over-harvested for the illegal pet trade (Stuart et al. 2006; Yang and Chan 2015; Ngo et al. 2019b). This is an additional threat to these range-restricted endemics from imperiled karstic environments (Grismer et al. 1997; Orlov et al. 2008; Ziegler et al. 2008; Nakamura et al. 2014; Yang and Chan 2015; Honda and Ota 2017; Zhou et al. 2018; Ngo et al. 2019a; Qi et al. 2020a,b; Zhu et al. 2020a,b). In fact, in areas of China and Vietnam, many populations have suffered huge declines in numbers, or even extirpation at some localities, due to the illegal commercial pet trade (Stuart et al. 2006; Yang and Chan 2015; Ngo et al. 2019b, 2021). We hope that this study will bring more clarity to the plight of this genus and continue to serve ongoing conservation and management programs.

\section{Acknowledgements}

For supporting fieldwork and issuing relevant permits, we thank the authorities of the Cat Ba National Park (CBNP), Hai Phong City, Huu Lien Nature Reserve, Lang Son Province, Bai Tu Long National Park, Quang Ninh Province, Tay Yen Tu Nature Reserve, Bac Giang Province, Yen $\mathrm{Tu}$ Nature Reserve and the Management Department of Ha Long Bay, Quang Ninh Province. We are thankful to N. H. Nguyen, C. T. Pham, T.Q. Phan, H.M. Tran (IEBR, Hanoi), H.Q. Nguyen (VNMN, Ha Noi), H.T. Ngo (HUS, Hanoi) for assistance in the field and laboratory. We are grateful to T. Pagel and C. Landsberg (Cologne Zoo), S.V. Nguyen, T.Q. Nguyen (IEBR, Hanoi), L.V. Vu and T.T. Nguyen (VNMN, Hanoi) for their support of conservation-based biodiversity research in Vietnam. Field surveys were partially funded by Cologne Zoo, the Wildlife Conservation Society ("WCS") John Thorbjarnarson Fellowship for Reptile Research Grant, the Mohamed bin Zayed Species Conservation fund (Project: 170515492) to H. N. Ngo, the Goniurosaurus yingdeensis Population Conservation Research of Guangdong Shimentai National Nature Reserve, China. Cologne Zoo is partner of the World Association of Zoos and Aquariums (WAZA): Conservation Project 07011, 07012 (Herpetodiversity Research, Amphibian and Reptilian Breeding and Rescue Stations). Researches of Hai Ngoc Ngo are funded by the German Academic Exchange Service (DAAD). We thank Dr. Hidetoshi Ota for his insight on the microhabitat preferences of the species of the Goniurosaurus kuroiwae species group.

\section{References}

Barbour T (1908) Some new reptiles and amphibians. Bulletin of the Museum of Comparative Zoology 51: 315-325.

Beaumont M, Wang J (2019) Conservation genetics. In: Balding D, Moltke I, Marioni J (eds), Handbook of Statistical Genomics: fourth edition. Wiley Online Library. https://doi.org/10.1002/9781119487845. $\operatorname{ch} 16$

Cabral JS, Wiegand K, Kreft H (2009) Interactions between ecological, evolutionary and environmental processes unveil complex dynamics of insular plant diversity. Journal of Biogeography 46: 1582-1597. https://doi.org/10.1111/jbi.13606

Cerrano C, Azzini F, Bavestrello G, Calcinai B, Pansini M, Sarti M, Thung D (2006) Marine lakes of karst islands in Ha Long Bay (Vietnam). Chemistry and Ecology 22: 489-500

Chambers G, MacAvoy, ES (1999) Molecular Genetic Analysis of Hybridization. Department of Conservation, Wellington, $29 \mathrm{pp}$.

Clements R, Sodhi NS, Schilthuizen M, Ng PKL (2006) Limestone karsts of Southeast Asia: imperiled arks of biodiversity. BioScience 56: 733-742. https://doi.org/10.1641/0006-3568(2006)56[733 :LKOSAI]2.0.CO;2

Clements R, Ng PKL, Lu XX, Ambu S, Schilthuizen M, Bradshaw CJA (2008) Using biogeographical patterns of endemic land snails to improve conservation planning for limestone karsts. Biological Conservation 141: 2751-2764. https://doi.org/10.1016/j.lbiocon.2008.08.011

Do T (2001) Characteristics of karst ecosystems of Vietnam and their vulnerability to human impact. Acta Geologica Sinica (English Edition) 75: 325-329. https://doi.org/10.1111/j.1755-6724.2001.tb00539.x

Do TC (2014) Distinctive features of the property of Cat Ba archipelago, Vietnam. Journal of Earth Science and Engineering 4: 271-283. https://doi.org/10.17265/2159-581X/2014.05.003

Erwin TL (1991) An evolutionary basis for conservation strategies. Science 253: 750-752. https://doi.org/10.1126/science.253.5021.750

Fay MF, Gargiulo R, Viruel J (2019) The present and future for population genetics, species boundaries, biogeography and conservation. Botanical Journal of the Linnean Society 191: 299-304. https://doi. org/10.1093/botlinnean/boz076

Forest F, Grenyer R, Rouget M, Davies JT, Cowling RM, Faith DP, Balmford A, Manning JC, Proches S, van der Bank M, Reeves G, Hedderson TAJ, Savolainen V (2007) Preserving the evolutionary potential of floras in biodiversity hotspots. Nature 445: 757-760. https://doi.org/10.1038/nature05587

Grant PR, Grant BR (2008) How and why species multiply: the radiation of Darwin's finches. Princeton University Press, Princeton, NJ.

Greene HW (2005) Organisms in nature as a central focus for biology. Trends in Ecology and Evolution 20: 23-27.

Grismer LL (1988) The phylogeny, taxonomy, classification, and biogeography of eublepharid geckos (Reptilia: Squamata). In "Phylogenetic Relationships of the Lizard Families" Ed by Estes R, Pregill, G Stanford University Press, California, pp 369-469.

Grismer LL, Ota H, Tanaka S (1994) Phylogeny, classification, and biogeography of Goniurosaurus kuroiwas (Squamata: Eublepharidae) from the Ryukyu Archipelago, Japan, with descriotion of a new subspecies. Zoological Science 11: 319-335.

Grismer LL, Viets BE, Boyle LJ (1999) Two new continental species of Goniurosaurus (Squamata: Eublepharidae) with a phylogeny and evolutionary classification of the genus. Journal of Herpetology 33: 382-393. http://dx.doi.org/10.2307/1565635 
Grismer LL, Wood PL Jr., Le MD, Quah ESH, Grismer JL (2020a) Evolution of habitat preference in species of Bent-toed geckos (Genus Cyrtodactylus Gray,1827) with a discussion of karst habitat conservation. Ecolology and Evolution 2020;00: 1-14.

Grismer LL, Chan KO, Oaks JR, Neang T, Lang S, Murdoch ML, Stuart BL, Grismer JL (2020b) A new insular species of the Cyrtodactylus intermedius (Squamata: Gekkonidae) group from Cambodia with a discussion of habitat preference and ecomorphology. Zootaxa 4830: 75-102. https://doi.org/10.11646/zootaxa.4830.1.3

Grismer LL, Wood Jr, PL, Thura MK, Zin T, Quah ESH, Murdoch ML, Grismer MS, Lin A, Kyaw H, Ngwe L (2018a) Twelve new species of Cyrtodactylus Gray (Squamata: Gekkonidae) from isolated limestone habitats in east-central and southern Myanmar demonstrate high localized diversity and unprecedented microendemism. Zoological Journal of the Linnean Society 182: 862-959. http://dx.doi. org/10.1093/zoolinnean/zlx057

Grismer LL, Wood Jr, PL, Anuar S, Grismer MS, Muin MA, Davis HR, Aguilar C, Klaback R, Cobos AJ, Aowphol A, Sites Jr, J (2016a) Two new Bent-toed Geckos of the Cyrtodactylus pulchellus complex from Peninsular Malaysia and multiple instances of convergent adaptation to limestone forest ecosystems. Zootaxa 4105: 401-429. https://doi.org/10.11646/zootaxa.4105.5.1

Grismer LL, Wood PL, Jr, Anuar S, Riyanto A, Ahmad N, Muin MA, Sumontha M, Grismer JL, Onn CK, Quah ESH, Pauwels OSA (2014) Systematics and natural history of Southeast Asian Rock Geckos (genus Cnemaspis Strauch, 1887) with descriptions of eight new species from Malaysia, Thailand, and Indonesia. Zootaxa 3880: 1-147. https://doi.org/10.1002/ece3.6961

Grismer LL, Wood PL Jr, Poyarkov NA, Le MD, Karunarathna S, Chomdej S, Suwannapoom C, Liu S, Che J, Quah ESH, Kraus F, Oliver PM, Riyanto, A, Pauwels OGS, Grismer JL (2021) Karstic landscapes are foci of species diversity in the world's third-largest vertebrate genus Cyrtodactylus Gray, 1827 (Reptilia: Squamata: Gekkonidae). Diversity 13: 183, (5) https://doi.org/10.3390/d13050183

Groth JG, Barrowclough GF (1999) Basal divergences in birds and the phylogenetic utility of the nuclear RAG-1 gene. Molecular Phylogenetics and Evolution 12: 115-123.

Harfoot MBJ, Newbold T, Tittensor DP, Emmott S, Hutton J, Lyutsarev V, Smith MJ, Scharlemann JPW, Purves DW (2014). Emergent global patterns of ecosystem structure and function from a mechanistic general ecosystem model. PLoS Biology 12, e1001841. https://dx. doi.org/10.1371/journal.pbio.1001841

Harvey MS, Rix MG, Framenau VW, Hamilton ZR, Johnson MS, Teale RJ, Humphreys G, Humphreys WF (2011) Protecting the innocent: studying short-range endemic taxa enhances conservation outcomes. Invertebrate Systematics 25: 1-10. https://doi.org/10.1071/IS11011

Heath TA, Hedtke SM, Hillis DM (2008) Taxon sampling and the accuracy of phylogenetic analyses. Journal of Systematics and Evolution 46: $239-257$.

Hoang DT, Chernomor O, von Haeseler A, Minh BQ, Vinh LS (2018) UFBoot2: Improving the ultrafast bootstrap approximation. Molecular Biology and Evolution 35: 518-522. https://doi.org/10.1093/ molbev/msx281

Holderegger R, Balkenhol N, Bolliger J, Engler JO, Gugeril F, Hochkirch A, Nowak C, Segelbacher G, Widmer A, Zachos FE (2019) Conservation genetics: linking science with practice. Molecular Ecology 28: 3848-3856. https://doi.org/10.1111/mec.15202

Honda M, Ota H (2017) On the live coloration and partial mitochondrial DNA sequences in the topotypic population of Goniurosaurus kuroiwae orientalis (Squamata: Eublepharidae), with description of a new subspecies from

Tokashikijima Island, Ryukyu Archipelago, Japan. Asian Herpetological Research 8: 96-107. https://doi.org/10.16373/j.cnki.ahr.170003

Honda M, Kurita T, Toda M, Ota H (2014) Phylogenetic relationships, genetic divergence, historical biogeography and conservation of an endangered gecko, Goniurosaurus kuroiwae (Squamata: Eublepharidae), from the central Ryukyus, Japan. Zoological Science 31: 309-320. https://doi.org/10.2108/zs130201

Huelsenbeck JP, Ronquist F, Nielsen R, Bollback JP (2001) Bayesian inference of phylogeny and its impact on evolutionary biology. Science 294: 2310-2314. https://doi.org/10.1126/science.1065889

Jombart T, Devillard S, Balloux F. 2010. Discriminant analysis of principal components: a new method for the analysis of genetically structured populations, BMC Genetics 11: 94.

Jonniaux P, Kumazawa Y (2008) Molecular phylogenetic and dating analyses using mitochondrial DNA sequences of eyelid geckos (Squamata: Eublepharidae). Gene 407: 105-115. https://doi.org/ 10.1016/j.gene.2007.09.023

Kaatz A, Grismer JL, Grismer LL (2021) Convergent evolution in ecomorphology and habitat preference in Bent-toed Geckos (Cyrtodactylus) from Peninsular Malaysia Vertebrate Zoology in press.

Kurita T, Honda M, Toda M (2008) Species delimitation and biogeography of the Ryukyu ground geckos, Goniurosaurus kuroiwae ssp. (Squamata: Eublepharidae), by use of mitochondrial and nuclear DNA analyses. Journal of Zoolological Systematics and Evolutionary Research 56: 209-222. https://doi.org/10.1111/jzs.12198

Liang B, Zhou RB, Liu YL, Chen B, Grismer LL, Wang N (2018) Renewed classification within Goniurosaurus (Squamata: Eublepharidae) uncovers the dual roles of a continental island (Hainan) in species evolution. Molecular Phylogenetics and Evolution 127: 646-654. https://doi.org/10.1016/j.ympev.2018.06.011

Lleonart J, Salat J, Torres GJ (2000) Removing allometric effects of body size in morphological analysis. Journal of Theoretical Biology 205: 85-93. https://doi.org/10.1006/jtbi.2000.2043

Losos JB (2010) Adaptive radiation, ecological opportunity, and evolutionary determinism. American Naturalist 175: 623-639.

Luo Z, Tang S, Jiang Z, Chen J, Fang H, Li C (2016) Conservation of terrestrial vertebrates in a global hotspot of karst in southwestern China. Scientific Reports. https://dx.doi.org/10.10.38/srep25717

Luu VQ, Bonkowski M, Nguyen TQ, Le MD, Schneider N, Ngo HT, Ziegler T (2016) Evolution in karst massifs, cryptic diversity among bent-toed geckos along the Truong Son Range with descriptions of three new species and one new country record from Laos. Zootaxa 4107: 101-140. https://doi.org/10.11646/zootaxa.4107.2.1

Meiri S (2018) Traits of lizards of the world: variation around a successful evolutionary design. Global Ecology and Biogeography 2108: 1-5. https://doi.org/10.1111/geb.12773

Minh BQ, Nguyen MAT, von Haeseler A (2013) Ultrfast approximation for phylogenetic bootstrap. Molecular Biology and Evolution 30: 1188-1195. https://doi.org/10.1093/molbev/mst024

Miller MA, Pfeiffer W, Schwartz T (2010) Creating the CIPRES Science Gateway for inference of large phylogenetic trees. In: Proceedings of the Gateway Computing Environments Workshop (GCE), 14 Nov. 2010, New Orleans, LA pp. 1-8. https://doi.org/10.1109/ GCE.2010.5676129

Mocquard F (1897) Notes herpétologiques. Bulleton of the Museum of Natural History, Paris 3: 211-217.

Moritz C, Patton JL, Schneider CJ, Smith TB (2000) Diversification of rainforest faunas: an integrated molecular approach. Annual Review 
of Ecology and Systematics 31: 533-563. https://doi.org/10.1146/ annurev.ecolsys.31.1.533

Nakamura Y, Takahashi A, Ota H (2014) A new, recently extinct subspecies of the Kuroiwa's Leopard Gecko, Goniurosaurus kuroiwae (Squamata: Eublepharidae), from Yoronjima Island of the Ryukyu Archipelago, Japan Acta Herpetologica 9: 61-73. https://doi.org/ 10.13128/Acta_Herpetol-13269

Nielsen SV, Oliver PM (2017) Morphological and genetic evidence for a new karst specialist lizard from New Guinea (Cyrtodactylus: Gekkonidae). Royal Society Open Science 20174 170781. https://doi. org/10.1098/rsos.170781

Ngo HN, Nguyen TQ, Phan TQ, van Schingen M, Ziegler T (2019b) A case study on trade in threatened Tiger Geckos (Goniurosaurus) in Vietnam including updated information on the abundance of the endangered G. catbaensis. Nature Conservation 33: 1-19.

Ngo HN, Le QT, Pham LM, Le MD, van Schingen M, Ziegler T (2019a) First record of the Cat Ba tiger gecko, Goniurosaurus catbaensis, from Ha Long Bay, Quang Ninh Province, Vietnam: microhabitat selection, potential distribution, and evidence of treats. Amphibian and Reptile Conservation 13: 1-13.

Ngo HN, Ziegler T, Nguyen TQ, Pham CT, Nguyen TT, Le MD, van Schingen M (2016) First population assessment of two cryptic tiger geckos (Goniurosaurus) from Northern Vietnam: Implications for conservation. Amphibian and Reptile Conservation 10: 34-45

Ngo HN, Nguyen HQ, Tran HM, Ngo HT, Le MD, Gewiss LR, van Schingen-Khan M, Nguyen TQ, Ziegler T (2021) A morphological and molecular review of the genus Goniurosaurus, including an identification key. European Journal of Taxonomy in press

Nguyen L-T, Schmidt HA, von Haeseler A, Minh BQ (2015). IQ-TREE: A fast and effective stochastic algorithm for estimating maximum likelihood phylogenies. Molecular Biology and Evolution 32: 268274. https://doi.org/10.1093/molbev/msu300

Nguyen TQ (2011) Systematics, ecology, and conservation of the lizard fauna in northeastern Vietnam, with special focus on Pseudocalotes (Agamidae), Goniurosaurus (Eublepharidae), Sphenomorphus and Tropidophorus (Scincidae) from this country. $\mathrm{PhD}$ thesis, University of Bonn, Bonn, Germany.

Nguyen VS, Ho TC, Nguyen QT (2009) Herpetofauna of Vietnam. Edition Chimaira, Frankfurt am Main.

Orlov NL, Ananjeva, NB, Nguyen TT (2020) New record and distribution of the genus Goniurosaurus Barbour, 1980 (Eublepharidae, Sauria, Reptilia) in Vietnam. Russian Journal of Herpetology 27: 179-184.

Orlov NL, Ryabow SA, Nguyen TT, Nguyen QT, Ho TC (2008) A new species of Goniurosaurus (Sauria: Gekkota: Eublepharidae) from north Vietnam. Russian Journal of Herpetology 15: 229-244.

Palumbi S, Martin A, Romano S, McMillan WO, Stice L. ,Grabowski G. (1991) The simple fool's guide to PCR. Version 2.0. University of Hawaii, Honolulu, pp 1-24.

Paradis E, Schliep K (2018) ape 5.0: an environment for modern phylogenetics and evolutionary analyses in R. Bioinformatics 35: 526528. https://doi.org/10.1093/bioinformatics/bty633

Pyron RA, Burbrink FT, Wiens JJ (2013) A phylogeny and revised classification of Squamata, including 4161 species of lizards and snakes. BMC Evolutionary Biology 1, 93.

Qi S, Grismer LL, Lyu ZT, Zhang L, Li PP, Wang YY (2020a) A definition of the Goniurosaurus yingdeensis group (Squamata, Eublepharidae) with the description of a new species. ZooKeys 986: 127-155. https://doi.org/10.3897/zookeys.986.47989
Qi S, Wang J, Grismer LL, Chen H-H, Lyu Z-T, Wang Y-Y (2020b) The Stoor Hobbit of Guangdong: Goniurosaurus gollum sp. nov., a cave-dwelling Leopard Gecko (Squamata, Eublepharidae) from South China. ZooKeys 991: 137-153. https://doi.org/10.3897/zookeys.991.54935

R Core Team (2018) R: A language and environment for statistical computing. R Foundation for Statistical Computing. Vienna. Available from: http://www.R-project.org (accessed 1 August 2018)

Rambaut A, Drummond AJ (2014) TreeAnnotator v1. 7.0. https://doi. org/10.1186/1471-2148-7-214

Rambaut A, Suchard MA, Xie D, Drummond AJ (2014). Tracer v1.6. https://doi.org/10.1093/sysbio/syy032

Reist JD (1986) A empirical evaluation of coefficients used in residual and allometric adjustment of size covariation. Canadian Journal of Zoology 64: 1363-1368. https://doi.org/10.1139/z86-203

Revell LJ (2012) Phytools: An R package for phylogenetic comparative biology (and other things), Methods in Ecology and Evolution 3: 217-223. https://doi.org/10.1111/j.2041-210x.2011.00169.x

Rolland J, Cadotte MW, Davies J, Devictor V, Lavergne S, Mouquet N, Pavoine S, Rodrigues A, Thuiller W, Turcati L, Winter M, Zupan L, Jabot F, Morlon H (2012) Using phylogenies in conservation: new perspectives. Biology Letters 8: 692-694. https://doi.org/10.1098/ rsbl.2011.1024

Ronquist F, Teslenko M, van der Mark P, Ayres DL, Darling A, Höhna B, Larget L, Liu L, Suchard MA, Huelsenbeck JP (2012) Mr. Bayes 3.2: efficient Bayesian phylogenetic inference and model choice across a large model space. Systematic Biology 61: 539-542. https://doi.org/10.1093/sysbio/sys029

Sgro CM, Lowe AJ, Hoffmann AA (2010) Building evolutionary resilience for conserving biodiversity under climate change. Evolutionary Applications. https://doi.org/10.1111/j.1752-4571.2010.00157.x

Sinervo B, Méndez-de-la-Cruz F, Miles DB, Heulin B, Bastiaans B, Villagrán-Santa Cruz M, Lara-Resendiz R, Martínez-Méndez N, Calderón-Espinosa ML, Meza-Lázaro RN, Gadsden H, Avila LJ, Morando M, De la Riva IJ, Sepulveda PV, Rocha CFD, Ibargüengoyta N, Puntriano CA, Massot M, Lepetz V, Oksanen TA, Chapple DG, Bauer AM, BranchWR, Clobert J, Sites Jr, JW (2006). Erosion of lizard diversity by climate change and altered thermal niches. Science 328: 894-899. https://doi.org/10.1126/science.1184695

Sterling E J, Hurley MM, Le MD (2006). Vietnam: A natural history. New Haven, CT, London: Yale University Press.

Stuart BL, Rhodin AG, Grismer LL, Hansel T. 2006. Scientific description can imperil species. Science 312: 1137. http://dx.doi org/10.1126/science.312.5777.1137b

Thorpe RS (1975) Quantitative handling of characters useful in snake systematics with particular reference to interspecific variation in the Ringed Snake Natrix natrix (L.). Biological Journal of the Linnean Society 7: 27-43. https://doi.org/10.1111/j.1095-8312.1975. tb00732.x

Thorpe RS (1983) A review of the numerical methods for recognizing and analyzing racial differentiation. In: Felsenstein $\mathrm{J}$ (Ed.), Numerical Taxonomy. NATO ASI Series. Series G: Ecological Sciences. Vol. 1. Springer-Verlag, Berlin, pp. 404-423. https://doi. org/10.1007/978-3-642-69024-2_43

Trifinopoulos J, Nguyen L-T, von Haesele A, Minh BQ (2016) W-IQTREE: a fast online phylogenetic tool for maximum likelihood analysis. Nucleic Acids Research 44: W232-W235. https://doi.org/ 10.1093/nar/gkw256 
Turan, C (1999) A note on the examination of morphometric differentiation among fish populations: The Truss System. Turkish Journal of Zoology, 23, 259-263.

Uetz, P, Hosek, J, eds. (2021) The Reptile database. http://www.reptile-database.org (accessed on 5 March 2021).

Vane-Wright RI, Humphries CJ, Williams PH (1991) What to protect? systematics and the agony of choice. Biological Conservation 55: 235-254. https://doi.org/10.1016/0006-3207(91)90030-D

von Oheimb PV, von Oheimb KCM, Hirano T, Do VT, Luong HV., Ablett J, Phanm SV, Naggs (2017) Competition matters: Determining the drivers of land snail community assembly among limestone karst areas in northern Vietnam. Ecology and Evoluition 28: 41364149. https://doi.org/10.1002/ece3.3984

Vu, NT, Nguyen TQ, Grismer LL, Ziegler T (2006) First record of the Chinese Leopard Gecko, Goniurosaurus luii (Reptilia: Eublepharidae) from Vietnam. Current Herpetology 25: 93-95.

Wainwright PC, Price SA (2016) The impact of organismal innovation on functional and ecological diversification. Integrative and Comparative Biology 56: 479-488.

Wang YY, Yang JH, Grismer LL (2013) A new species of Goniurosaurus (Squamata: Eublepharidae) from Libo, Guizhou Province, China. Herpetologica 69: 214-226.

Wiens JJ (1998) Does adding characters with missing data increase or decrease phylogenetic accuracy? Systematic Biology 47: 625-640.

Wiens JJ, Morrill MC (2011) Missing data in phylogenetic analysis: reconciling results from simulations and empirical data. Systematic Biology 60: 719-731. https://doi.org/10.1093/sysbio/syr025

Wilcox TP, Zwickl DJ, Heath TA, Hillis, DM (2002) Phylogenetic relationships of the Dwarf Boas and a comparison of Bayesian and bootstrap measures of phylogenetic support. Molecular Phylogenetics and Evolution 25: 361-371. https://doi.org/10.1016/S10557903(02)00244-0

Winter M, Devictor V, Schweiger O (2012) Phylogenetic diversity and nature conservation: where are we? Trends in Ecology and Evolution 28: 199-204. https://doi.org/10.1016/j.tree.2012.10.015
Vázquez DP, Gittleman JL (1998) Biodiversity conservation: does phylogeny matter? Current Biology 8: R379-R381. https://doi. org/10.1016/S0960-9822(98)70242-8

Vu NT, Nguyen TQ, Grismer LL, Ziegler T (2006) First record of the Chinese leopard gecko, Goniurosaurus luii (Reptilia: Eublepharidae) from Vietnam. Current Herpetology 25: 93-95.

Williams PH, Humphries CJ, Vane-Wright RI (1991) Measuring biodiversity: taxonomic relatedness for conservation priorities. Australian Systematic Botany 4: 665-679. https://doi.org/10.1071/SB9910665

Yang JH, Chan BP (2015) Two new species of the genus Goniurosaurus (Squamata: Sauria: Eublepharidae) from Southern China. Zootaxa 3980: 67-80. https://doi.org/10.11646/zootaxa.3980.1.4

Zhou R, Wang N, Chen B, Liang B (2018) Morphological evidence uncovers a new species of Goniurosaurus (Squamata: Eublepharidae) from the Hainan Island, China. Zootaxa 4369: 281-291. https://doi. org/10.11646/zootaxa.4369.2.8

Zhou R, Peng X, Hou M, Yuan F (2019) A new species of genus Goniurosaurus-G. sinesis. Journal of Shihezi University (Natural Science) 37: 549-556.

Zhu XY, Chen GY, Román-Palacios C, Li Z, He ZQ (2020a) Goniurosaurus gezhi sp. nov., a new gecko species from Guangxi, China (Squamata: Eublepharidae). Zootaxa 4852: 211-222. https://doi. org/10.11646/zootaxa.4852.2.6

Zhu XY, Shen CZ, Liu YF, Chen L, Li Z, He ZQ (2020b) A new species of Goniurosaurus from Hainan Island, China based on molecular and morphological data (Squamata: Sauria: Eublepharidae). Zootaxa 4772: 349-360. https://doi.org/10.11646/zootaxa.4772.2.6

Ziegler T, Nguyen TQ, Schmitz A, Stenke R, Rösler H (2008) A new species of Goniurosaurus from Cat Ba Island, Hai Phong, Northern Vietnam (Squamata: Eublepharidae). Zootaxa 1771: 16-30. https:// doi.org/10.11646/zootaxa.1771.1.2

Zwickl DJ, Hillis DM (2002) Increased taxon sampling greatly reduces phylogenetic error. Systematic Biology 51: 588-598. https://doi. org/10.1080/10635150290102339 